\title{
SRSF1 as a novel interacting partner for IFITM1/3 unravels the emergent role of
} 2 IFITM1/3 mediating protein expression

3

Maria Gómez-Herranz ${ }^{a, c^{*}}$, Jakub Faktor ${ }^{b, c}$, Marcos Yébenes Mayordomo ${ }^{a, c}$, Magdalena Pilch ${ }^{a, c}$, Lenka Hernychova $^{b}$, Kathryn L. Ball ${ }^{a}$, Borivoj Vojtesek ${ }^{b}$, Ted R. Hupp ${ }^{a, b, c}$. and Sachin Kote ${ }^{c^{*}}$

aUniversity of Edinburgh, Institute of Genetics and Cancer, Edinburgh, United Kingdom; 'Masaryk Memorial Cancer Institute, Research Centre for Applied Molecular Oncology, Brno, Czech Republic; International Centre for Cancer Vaccine Science, University of Gdańsk, Gdansk, Poland

* Correspondence should be addressed to:

Maria Gómez-Herranz. International Centre for Cancer Vaccine Science, University of Gdańsk, Gdansk, Poland. Email address: maria.gomez@ug.edu.pl

Sachin Kote. International Centre for Cancer Vaccine Science, University of Gdańsk, Gdansk, Poland. Email address: sachin.kote@ug.edu.pl

Running title: IFITM1/3 is associated with SRSF1 and mediates protein expression

Author Contributions: MGH, and TRH designed research; MGH, JF, MYM, MP, and LH performed research and analyzed data; MGH and TRH wrote the paper; KB, BV, TRH, and SK supervised.

Conflicts of Interest: The authors declare no conflict of interest.

Keywords: Interferon (IFN), mRNA, ribosome, interferon-induced transmembrane 1 and 3 (IFITM1/3), isoform of serine and arginine-rich splicing factor 1 (SRSF1).

Funding: This work was supported with the European Regional Development Fund - Project ENOCH (No. CZ.02.1.01/0.0/0.0/16_019/0000868), MH CZ - DRO (MMCI, 00209805) and Czech Science Foundation (GACR) 18-23773Y (MN, NF); the BBSRC RASOR consortium (BB/C511599/1; United Kingdom); This research was funded by POWROTY/Reintegration program of the Foundation for Polish Science cofinanced by the European Union under the European Regional Development Fund (project POIR.04.04.00-00-3E52/17-00) and The International Centre for Cancer Vaccine Science project carried out within the International Research Agendas program of the Foundation for Polish Science co-financed by the European Union under the European Regional Development Fund(project MAB/2017/3).

Abstract: IFITM proteins play a role in cancer cell progression through undefined mechanisms. Here, we propose an emergent role of IFITM1/3 regulating protein synthesis. SBPtagged IFITM1 protein was used to identify an association of IFITM1 protein with the cytosolic isoform of SRSF1 that transports mRNA to the ribosome. This cytosolic association was confirmed in situ using proximity ligation assays for SRSF1 and IFITM1/3, suggesting a role associated with translation. Accordingly, IFITM1/3 were shown to interact with HLA-B mRNA in response to IFN $\gamma$ stimulation using RNA-protein proximity ligation assays. In addition, shotgun RNA sequencing in IFITM1/IFITM3 null cells and wt-SiHa cells indicated that reduced HLA-B gene expression does not account for lowered HLA-B protein synthesis in response to IFN $\gamma$. Furthermore, ribosome profiling using sucrose gradient sedimentation identified a reduction in 805 ribosomal fraction an IFITM1/IFITM3 null cells compared to their wild-type counterpart, partially reverted by IFITM1/3 complementation. Our data all together link the binding of IFITM1/3 proteins to HLA-B mRNA and 
SRSF1 as a mechanism to catalyze the synthesis of target proteins, suggesting an RNA chaperonin role for IFITM1/3 proteins.

Significance: IFITMs are widely studied for their role in inhibiting viruses, and multiple studies have associated IFITMs with cancer progression. However, mechanistic insights are not well understood. Our study proposes that IFITMs have a role regulating protein synthesis, a pivotal function highly relevant for viral infection and cancer progression. Our results suggest that IFITM1/3 is present in the ribosomal fraction and regulates particular protein expression; among them, we identified HLA-B. Changes in HLA-B expression could impact the presentation and recognition of oncogenic antigens on the cell surface by cytotoxic $T$ cells and, ultimately, limit tumor cell eradication. In addition, the role of IFITMs mediating protein translation is relevant, as has the potential of regulating the expression of viral and oncogenic proteins.

\section{Introduction}

Multiple oncogenic pathways selectively modulate the expression of mRNAs, and in addition, regulation of protein expression is essential for cancer development (Robichaud et al., 2019). Thus, there is a particular scientific interest to unravel which cellular components orchestrate the translation of specific mRNA products associated with tumor progression. Indeed, control of cancerspecific translation is emerging as a new anticancer strategy where therapeutic drugs inhibit mRNA translation in a selective manner ( $\mathrm{Xu}$ and Ruggero, 2020).

Furthermore, interferons (IFNs) form a family of cytokines originally discovered to respond in opposition to the adverse effects of the flu virus; however, subsequent biological roles described for IFNs include activity against cancer development (Platanias, 2005). In this regard, IFNs are used in cancer treatment (Tamura et al., 1987; Pujade-Lauraine et al., 1996; Windbichler et al., 2000; Marth et al., 2006; Alberts et al., 2008; Parker, Rautela and Hertzog, 2016; Ives et al., 2017; van der Kooij et al., 2020) due to their ability to inhibit proliferative pathways, promote cellular apoptosis and increase the activity of the immune system (Budhwani, Mazzieri and Dolcetti, 2018).

Although relatively elevated doses of IFNs show protective effects against tumor progression (Wang, Rahbar and Fish, 2011; Booy, Hofland and van Eijck, 2015; Green et al., 2016), continuous low production of IFN stimulates the expression of the interferon resistance DNA damage signature (IRDS). The IRDS is comprised of a small subset of ISGs (Weichselbaum et al., 2008; Cheon, Borden and Stark, 2014) that promote tumor development by acquiring resistance to DNA damage, scaping immune surveillance, and increasing metastatic spread (Wallace, Martin and Ambs, 2011; Kolosenko et al., 2015). Thus, IFNs can mediate both cancer suppression and growth depending on context (Jorgovanovic et al., 2020).

There are described three protein families within the mammalian IFN tree; type I (IFN $\alpha$, IFN $\beta$, IFNe, IFNk and IFN $\omega$ ), type II (IFN $\gamma$ ) and type III (IFN $\lambda$ ) (Bekisz et al., 2004; Borden et al., 2007). The core mechanism of action of IFNs involves activating the JAK kinase-STAT signaling pathway that induces the transcription of numerous interferon-stimulated genes (ISGs) (Williams, 1991; Darnell, Kerr and Stark, 1994), including IFITM1/2/3.

The immune-related interferon-induced transmembrane (IFITM) protein family are composed of three members; IFITM1, IFITM2, and IFITM3 (Bailey et al., 2014). IFITM1 is slightly different from IFITM2 and IFITM3, with some studies proposing that IFITM1 is uniquely expressed 
on the cell surface (Weston et al., 2014; Jia et al., 2015). In addition, only a limited number of interacting partners have been identified for the IFITMs (Xu, Yang and Hu, 2009; Amini-Bavil-Olyaee et al., 2013; Narayana et al., 2015; Yu, Xie, Ng, Lum, M.-Y. Cai, et al., 2015). However, a growing body of research has proven that components of the IFITM family are capable of attenuating the propagation of RNA virus such as influenza A virus (IAV), West Nile virus (WNV), dengue virus, Severe Acute Respiratory Syndrome (SARS) coronavirus, filoviruses, Vesicular Stomatitis Virus (VSV), and Hepatitis C virus (HCV) (Brass et al., 2009; Bailey et al., 2014).

In addition to the widely studied anti-viral function of the IFITMs, IFITM1 and IFITM3 also function as a pro-oncogenic proteins whose expression has been reported in various cancers such as breast, cervix, colon, leukemia, ovary, brain, and esophagus (Fan et al., 2008; Györffy et al., 2008a; Weichselbaum et al., 2008; Wu et al., 2011; Borg et al., 2016a; Ogony et al., 2016; Sari, Y.-G. Yang, et al., 2016; Liu et al., 2020; Wang et al., 2020). Moreover, IFITM1 is an IRDS gene expressed upon radiation resistance. Hence, the protective effect described for IFNs against tumors is not well reflected in the role of the IFN-induced IFITM proteins concerning cancer (Weichselbaum et al., 2008; Khodarev, Roizman and Weichselbaum, 2012). Nonetheless, the molecular mechanism whereby IFITM1 and IFITM3 promote cancer growth or mediates viral restriction is not well-defined.

Overall, the IFITM functions associated with blocking viral infection, IFITM proteins can reduce HIV-1 viral protein synthesis by preferentially excluding viral mRNA transcripts from translation (Lee et al., 2018) providing an intracellular function for the IFITM family linked to suppressed viral propagation. This is consistent with our previous research where we found a translational role for the IFITM family in the context of cancer; deletion of IFITM1/3 genes suppresses the expression of a subset of proteins whose synthesis is mediated by IFN $\gamma$. Interestingly, HLA-B, which is a component of the IRDS was significantly identified (Gómez-Herranz et al., 2019). This indicates that IFITM1/3 can regulate the synthesis of some anti-viral in addition to cancer-associated gene products.

In this report, we further define the molecular mechanism whereby genetic ablation of IFITM1 and IFITM3 attenuates the synthesis of a subset of IFN-responsive proteins despite IFITM1/3knockout cell still retaining the ability to mediate IFN-induced gene expression. Here, we show that IFITM1/3 proteins can interact with the cytosolic translation factor SRSF1 and HLA-B mRNA. In addition, we identified changes in the $80 \mathrm{~S}$ ribosomal fraction in the absence of IFITM1/3 expression. Taking all together, this provides additional support for an RNA-binding and translational role for the IFITM family of proteins, as reported in response to HIV infection (Lee et al., 2018).

\section{Materials and Methods}

\section{Cell culture}

The wt-SiHa cells and IFITM1/IFITM3 null cells, that were described previously (GómezHerranz et al., 2019) were grown in RPMI 1640 medium (Invitrogen, USA) supplemented with 10\% $(\mathrm{v} / \mathrm{v})$ fetal bovine serum (Labtech, UK) and 1\% penicillin/streptomycin (Invitrogen, USA) and incubated at $37^{\circ} \mathrm{C}$ with $5 \% \mathrm{CO}_{2}$.

\section{Western blotting}

Protein from lysed samples was quantified using the Bradford (Bradford, 1976) Protein Assay Dye Reagent (Bio-Rad, USA). Proteins were resolved by SDS-PAGE using 15\% gels and transferred 
onto nitrocellulose membranes (Amersham Protran, GE Healthcare, USA). Immunoblots were processed by enhanced chemiluminescence (ECL) and quantified as RLU.

Antibodies

Proteins were detected using the following primary antibodies: mouse monoclonal antibodies were generated to a peptide that is identical in IFITM1 and IFITM3 and their characterization was described previously (Gómez-Herranz et al., 2019). As this panel of monoclonal antibody cannot distinguish between the IFITM1 and IFITM3 proteins, the text specifically states that IFITM1 and IFITM3 proteins (shortened to IFITM1/3) were measured when using these antibodies. Other sources of antibodies include Mouse monoclonal anti-IFITM2 (Proteintech), rabbit polyclonal anti-SRSF1 (Thermo Fisher Scientific), rabbit polyclonal anti-HLA-B (Thermo Fisher Scientific), rabbit polyclonal anti-RPL7a (Cell Signaling), mouse monoclonal anti- $\beta$-ACTIN (Sigma-Aldrich) and mouse monoclonal anti-GAPDH (Abcam).

\section{Trichloroacetic acid (TCA) precipitation}

Proteins were precipitated from individual sucrose gradient fractions by TCA precipitation. While adding $10 \mu \mathrm{l}$ of $1 \mu \mathrm{g} / \mu \mathrm{l}$ of Bovine Serum Albumin (BSA) to each prechilled eluate followed by the addition of ice-cold TCA $(90 \mu \mathrm{l})$, then was mixed and incubated on ice for $60 \mathrm{~min}$. The fractions were then centrifuged at $10,000 \mathrm{~g}$ at $4^{\circ} \mathrm{C}$ for $10 \mathrm{~min}$. The pellet was again centrifuged to remove any residual supernatant, washed with $250 \mu \mathrm{l}$ of ice-cold acetone and centrifuged at $4^{\circ} \mathrm{C}$ for $5 \mathrm{~min}$. Finally, the supernatant was discarded and a visible small white precipitate was air dried. Protein was then resuspended in $2 x$ sample buffer to proceed with the immunoblot.

\section{Immunofluorescence}

The wt-SiHa and IFITM1/IFITM3 null cells were non-stimulated and stimulated with 100 $\mathrm{ng} / \mathrm{ml} \mathrm{IFN} \gamma$ for $24 \mathrm{~h}$. Cells were fixed with $4 \%$ (v/v) paraformaldehyde in PBS at RT for $15 \mathrm{~min}$, washed with PBS three times, and permeabilized using 0.25\% triton X-100 in PBS at RT for 10 min. Then, the cells were again washed with PBS three times and blocked with 3\% BSA in PBS for $1 \mathrm{~h}$. The primary antibody was incubated at appropriate dilution (typically 1:1000) overnight at $4{ }^{\circ} \mathrm{C}$. Depending on which host species the primary antibody been generated, Alexa Fluor 488 goat antimouse (Invitrogen). Alexa Fluor 594 donkey anti-rabbit (Invitrogen) or Alexa Fluor 594 goat antimouse (Invitrogen) secondary antibody was incubated at RT for $1 \mathrm{~h}$. Coverslips were washed three times with PBS in between each step. Cells were incubated in DAPI (Invitrogen) diluted at 1:10,000 with $\mathrm{dH}_{2} \mathrm{O}$ for 5 min to stain the nucleus. An additional three washes with $\mathrm{dH}_{2} \mathrm{O}$ for 5 min were performed. A single drop of Fluorescence Mounting Medium (S3023, Dako, Denmark) was used to mount the cells on the slide. The fluorescent signal was detected using a Zeiss Axioplan 2 microscope (63x or 100x oil immersion objective). Images were acquired by Micro-Manager 1.4 software. Images were processed in Image 2.0 software.

The following parameters were considered while designing the primers: Firstly, primers 
GATGTGGATCACGGTGGAC-3')， IRF1 (F: 5'-CTCTGAAGCTACAACAGATGAG-3'; R : 5'GTAGACTCAGCCCAATATCCC-3'), ISG15 (F: 5'-GAGGCAGCGAACTCATCTTT-3'; R: 5'AGCATCTTCACCGTCAGGTC-3'), HLA-B (F: 5'-CACTGAGCTTGTGGAGACCA-3'; R: 5'ATGACCACAACTGCTAGGACA-3'), B2M (F: 5'-CTCGCTCCGTGGCCTTAG-3'; R: 5'GGATGAAACCCAGACACATAGC-3'), STAT1 (F: 5'-CCATCCTTTGGTACAACATGC-3'; R: 5'TGCACATGGTGGAGTCAGG-3'), and B-ACTIN (F: 5'-CATGTACGTTGCTATCCAGGC-3'; R: 5'CTCCTTAATGTCACGCACGAT-3') genes. Designing IFITM1 and IFITM3 primers target the unique C-terminal and $\mathrm{N}$-terminal regions respectively; the specific gene products were as follows, including gene name, gene number, transcript, transcript number; IFITM1; ENSG00000185885, IFITM1-202, ENST00000408968.4; IFITM3, ENSG00000142089, IFITM3-201， ENST00000399808.5; IRF1, ENST00000379389.4; HLA-B, ENSG00000234745, HLA-B-249, ENST00000412585.7; B2M, ENSG00000166710， B2M-204， ENST00000558401.6; STAT1， ENSG00000115415， STAT1-201， ENST00000361099.7; B-ACTIN, ENSG00000075624, ACTB-201, ENST00000331789.11.

Additional parameters were that all amplicons were expected to have a product size around 150-250 bp and with a melting temperature difference under $1^{\circ} \mathrm{C}$ between primers, as multiple genes were run in parallel using the same PCR plates. Designed primer sequences were analyzed by BLAST to ensure there were no additional amplified products. RT-qPCR was run under the same conditions for all the different transcripts. Melting curve analysis was performed, to define the specificity of each primer pair (data not shown). Three technical replicates from three biological replicates were set for each sample condition and the raw $\mathrm{Ct}$ values of all samples were defined (data not shown). To allow a stringent analysis, Ct expression values were less than one unit difference between each technical triplicate. Relative Ct expression values were normalized with a housekeeping gene, b-ACTIN. The analysis of gene expression was taken from the Ct values obtained by RT-qPCR, normalized into a relative expression using the formula 2-DCt where $\mathrm{DCt}$ is the difference between the $\mathrm{Ct}$ of the transcript of interest and the Ct of b-ACTIN (Fig 3A).

The wt-SiHa and IFITM1/IFITM3 null cells were grown and processed as described in the immunofluorescence method. Primary antibodies pairs from different species were incubated overnight on the fixed, permeabilized, and blocked cells. Depending on requirements of the experiment, the following combination of antibodies were incubated for $18 \mathrm{~h}$ at $4^{\circ} \mathrm{C}$ : the IFITM1/IFITM3 mouse monoclonal (1:500 dilution) with the SRSF1 rabbit polyclonal (1:250 dilution), or the IFITM1/IFITM3 mouse monoclonal (1:500 dilution) with the rabbit monoclonal anti-BIOTIN (1:200 dilution); the IFITM1/IFITM3 mouse monoclonal (1:500 dilution) with the rabbit polyclonal anti-RPL7a (1:250 dilution). Samples were incubated with the PLA probes; probe-mouse MINUS (DUO92004, Sigma-Aldrich, USA) and probe anti-rabbit PLUS (DUO92002, Sigma-Aldrich, USA) at $37^{\circ} \mathrm{C}$ for $1 \mathrm{~h}$. Samples were washed three times with buffer A (150 mm NaCl, $10 \mathrm{mM}$ Tris Base, $0.05 \%$

$210(\mathrm{v} / \mathrm{v})$ Tween-20, $\mathrm{pH}$ 7.4) for $5 \mathrm{~min}$ and then samples were incubated with ligation buffer $(8 \mu \mathrm{l}$ of $5 \mathrm{x}$

211 ligation stock (New England Biolabs, USA), $1 \mu \mathrm{l}$ ligase and $31 \mu \mathrm{l}$ of ultrapure water on each coverslip) 212 at $37^{\circ} \mathrm{C}$ for $30 \mathrm{~min}$. Samples were again washed three times with buffer A for $5 \mathrm{~min}$ and incubated 213 with amplification buffer at $37^{\circ} \mathrm{C}$ for $2 \mathrm{~h}$. Reagents are from Duolink in Situ Detection Reagents Green 214 assays (DUO92014, Sigma-ALdrich, USA). Samples were washed twice with buffer A, three times 
with buffer $\mathrm{B}(100 \mathrm{mM} \mathrm{NaCl}, 50 \mathrm{mM}$ Tris base, $\mathrm{pH} 7.5)$, and once with $0.01 \mathrm{x}$ buffer $\mathrm{B}$. Cells were incubated in DAPI (Invitrogen) diluted at 1:10,000 with $0.01 \times$ buffer B for 5 min to stain the nucleus.

217 An additional 2 washes with $0.01 x$ buffer B for 5 min were performed prior to mounting. The fluorescent signal was detected using a Zeiss Axioplan 2 microscope (63x or 100x oil immersion objective). Images were acquired by Micro-Manager 1.4 software. Images were processed in ImageJ 2.0 software.

RNA in situ hybridization-PLA (rISH-PLA)

The wt-SiHa cells and IFITM1/IFITM3 null cells were non-stimulated and IFN $\gamma$-stimulated for $24 \mathrm{~h}$. Cells were fixed with 4\% paraformaldehyde in PBS at RT for $20 \mathrm{~min}$ and washed with PBS for $10 \mathrm{~min}$. Then, samples were incubated in $70 \%(\mathrm{v} / \mathrm{v})$ ethanol overnight. Cells were then washed in PBS for 30 min and permeabilized with $0.05 \%$ CHAPS and 0.4\% Triton X-100 for 10 min at RT. Next, samples were treated with hybridization buffer for $30 \mathrm{~min}$ at RT. Samples were incubated for hybridization with $40 \mu \mathrm{l}$ of hybridization buffer (10\% (v/v) formamide, 2 X SSC, $0.2 \mathrm{mg} / \mathrm{mL}$ E. coli 522 tRNAs, $0.2 \mathrm{mg} / \mathrm{mL}$ sheared salmon sperm DNA and $2 \mathrm{mg} / \mathrm{mL}$ BSA) containing $50 \mathrm{ng}$ of or HLA-Bbiotin DNA probe (5' TGTCCTAGCAGTTGTGGTCATCGGAGCTGTGGTCGCTGCTGTGAT-biotin 3') (Sigma-Aldrich, USA) in a humidified chamber overnight. Prior to that, $5 \mu \mathrm{l}$ of probe diluted in water was denatured for $5 \mathrm{~min}$ and chilled on ice for $5 \mathrm{~min}$. Then, samples were washed with 2X SSC and $10 \%$ formamide at RT, twice with hybridization buffer at $37{ }^{\circ} \mathrm{C}, 2 \mathrm{XSSC}$ at RT, and finally with PBS at RT. Each wash was carried out for $20 \mathrm{~min}$. Next, samples were blocked with $3 \%$ BSA and $0.1 \%$ saponine in PBS at RT for $30 \mathrm{~min}$. After that, they were incubated with rabbit anti-BIOTIN and mouseanti-IFITM1/IFITM3 at RT for $2 \mathrm{~h}$. The subsequent steps were performed as described in the PLA methodology section (above).

Bioinformatic analysis of the RNA-sequencing

Biological triplicates of wt-SiHa cells and IFITM1/IFITM3 null cells were non-stimulated and stimulated $24 \mathrm{~h}$ with $100 \mathrm{ng} / \mathrm{ml} \mathrm{IFN} \gamma$. Total RNA was extracted from frozen cell pellets following the instruction manual (RNeasy Mini kit, Qiagen, Germany). RNA samples of IFN $\gamma$-stimulated and nonstimulated wt-SiHa cells and IFITM1/IFITM3 null cells were processed by Otogenetics (USA, Georgia) for paired end RNA sequencing analysis, using an Illumina HiSeq 2500 and designated 20 million reads. The pair of fastq files obtained from the sequencer were checked for quality control, merged and processed using CLC Genomic Workbench 12.0 to obtain the total RNA expression levels. GRCh38 was taken as the human reference genome with the following settings: mismatch cost: 2 , insertion cost: 3 , deletion cost: 3 . The results were compared using RNA gene expression for each condition, creating four different scatter plots (Fig 3B) that compared IFN $\gamma$ stimulated to nonstimulated conditions, and wt-SiHa cells to IFITM1/IFITM3 null cells. Comparisons were performed taking the transcripts per million (TPM) values as reporting abundances and Log2 (TPM condition 1 versus $\log 2$ (TPM condition 2) as comparison values. An additional heat map was generated with the list of IRDS genes to compare the gene expression of these genes of interest across samples (SI Appendix, Fig. S4). Following the same parameters, another heat map was created using ggplot2 to compare isoform switches using sum of RNA transcript expression or the RNA transcript expression level of particular transcripts. The color code represented in the heat map shows; red when a gene is highly expressed and purple to blue for non-expressed and under-expressed values. The values in 
white represent a low level of expression becoming non-significant. Finally, the values in grey are for the genes in which TPM was equal to 0 .

\section{Sucrose gradient sedimentation}

For experiments processing ribosomal fractions using the wt-SiHa cells and IFITM1/IFITM3 null cells (Fig 5), the cultures were stimulated with $100 \mathrm{ng} / \mathrm{ml} \mathrm{IFN} \gamma$ for $24 \mathrm{~h}$ prior to cell harvesting. In the complementation assays (SI Appendix, Fig. S5D-F), whereby IFITM1/IFITM3 null were transfected with either the IFITM1 and IFITM3 expression plasmids or empty vector controls, $24 \mathrm{~h}$ after transfection, the cells were then stimulated with $100 \mathrm{ng} / \mathrm{ml} \mathrm{IFN} \gamma$ for $24 \mathrm{~h}$. In all cases, the cells were treated with $50 \mu \mathrm{g} / \mathrm{ml}$ cycloheximide (Merck Chemicals, Germany) for $30 \mathrm{~min}$. Then, cells were washed in PBS (phosphate buffered saline; $137 \mathrm{~mm} \mathrm{NaCl}, 2.7 \mathrm{mM} \mathrm{KCL}, 10 \mathrm{~mm} \mathrm{Na2HPO4}$, and 1.8 $\mathrm{mm} \mathrm{KH2PO4)} \mathrm{containing} 1 \mathrm{x}$ RSB, harvested by centrifugation at 7,000 rpm for 1 min at $4{ }^{\circ} \mathrm{C}$, and frozen at $-80^{\circ} \mathrm{C}$. Lysis was carried out by resuspending the cell pellets in $250 \mu \mathrm{l}$ of RSB/RNasin buffer and $250 \mu \mathrm{l}$ PEB (Polysome extraction buffer) buffer. Mechanical disruption of the cell lysate was carried out by passing the lysate though a needle (25G) five times. Lysates were incubated on ice for $10 \mathrm{~min}$ and centrifuged at $10,000 \mathrm{~g}$ for $10 \mathrm{~min}$ at $4^{\circ} \mathrm{C}$. Lysates were processed as described (Sanford et al., 2004). Sucrose gradients (10-45\%) were prepared using a BioComp gradient master. Lysates were applied onto the gradient and centrifuged at 41,000 rpm for $2 \mathrm{~h} 30 \mathrm{~min}$ using a SW41 rotor. Fraction collection was performed using a BioComp gradient station model 153 (BioComp Instruments, Canada). Analysis of ribosomal fractions was performed as biological triplicate. The 10X RSB stock solution contained $200 \mathrm{mM}$ Tris-Hcl ( $\mathrm{pH}$ 7.5), $1 \mathrm{M} \mathrm{KCL}$, and $100 \mathrm{mM} \mathrm{MgCl}$. The RSB/RNasin buffer $(2 \mathrm{ml})$ was prepared fresh and contained $200 \mathrm{ul}$ of $10 \mathrm{X}$ RSB and $50 \mathrm{ul} \mathrm{RNasin}$ (N2511, Promega, USA). The PEB buffer $(10 \mathrm{ml}$ ) was made fresh and contained $1 \mathrm{ml}$ of $10 \mathrm{x}$ RSB, 50 ul of NP40, and 1 protease inhibitor tablet (Complete Mini-EDTA free EASYpack, 034693159001, Roche/Sigma-Aldrich). In addition, sample preparation for western blotting required deproteinization of crude samples and was performed using the trichloroacetic acid (TCA) method.

\section{Cloning, transfection and affinity purification of IFITM1 from heavy isotope labeled cells}

IFITM1 cDNA was cloned by PCR into pEXPR-IBA105 expression vector containing a SBP tag at the N-terminus of the coding region (SBP vector, IBA, Germany). Cells were grown as biological triplicates for 10 days with 5 passages in RPMI SILAC media before transfection (Dundee Cell Products, UK). Cells were isotopically labelled with light media; L-[12C614N4] arginine (R0) and L[12C614N2] lysine (K0) and heavy media; L-[13C614N4] arginine (R6) and L-[13C614N2] lysine (K6). For transfection, cells were grown to approximately $80 \%$ confluency in light and heavy media and transfected using Attractene (\#301007, Qiagen, Germany) with SBP-empty vector (control cells) and SBP-IFITM1 (SI Appendix, Fig. S2). At 24 and $48 \mathrm{~h}$ after transfection, cells were washed twice in ice cold PBS and scraped into $0.1 \%$ Triton buffer for $30 \mathrm{~min}$ on ice. Equal amounts of protein were used for performing the pull down. Total protein extracts were measured by Bradford assay. For affinity purification, the cells were washed twice in cold PBS and scraped directly into IP buffer $(100 \mathrm{mM}$ KCl, 20 mM HEPES pH 7.5, 1 mM EDTA, 1 mM EGTA, 0.5 mM Na3VO4, 10 mM NaF, 10\% (v/v) glycerol, protease inhibitor mix, and $0.1 \%$ Triton X-100). The lysate was then incubated for $30 \mathrm{~min}$ on ice and centrifuged at $13,000 \mathrm{rpm}$ for $15 \mathrm{~min}$ at $4{ }^{\circ} \mathrm{C}$. Then cell lysate was added to Streptavidin Agarose conjugated beads (Millipore, USA) and incubated for $2 \mathrm{~h}$ with gentle rotation. The proteins 
were eluted from the beads using Elution Buffer (20 mM HEPES pH 8, 2 mM DTT, and 8 M Urea). The eluted samples (whole volume) from light and heavy SILAC medium labeled cells were mixed together.

Peptide generation using FASP

Proteins eluted after SBP pull-down were processed by the filter-aided sample preparation protocol method (FASP) (Wiśniewski et al., 2009) according to a workflow described in GómezHerranz et al. (Gómez-Herranz et al., 2019). Briefly, protein concentration was determined using the RC-DC protein assay (Bio-rad, USA). Approximately $100 \mu \mathrm{g}$ of protein dissolved in $20 \mathrm{mM}$ HEPES pH 8, 2 mM DTT, and 8 M Urea was added to a $10 \mathrm{kDa}$ spin filter column (Microcon, Merck-Millipore, USA), on-filter reduced, alkylated and trypsin digested to peptides. Tryptic peptides were then desalted using C18 micro-spin columns (Harvard Apparatus, USA) (Gómez-Herranz et al., 2019).

\section{LC-MS/MS analysis of SILAC labeled samples}

Tryptic peptides from isotopically labeled cells were separated using an UltiMate 3000 RSLCnano chromatograph (Thermo Fisher Scientific, USA). Tryptic peptides were loaded onto a precolumn ( $\mu$-precolumn, $30 \mu \mathrm{m}$ i.d., $5 \mathrm{~mm}$ length, C18 PepMap 100, $5 \mu \mathrm{m}$ particle size, $100 \AA$ A pore size) and separated using an Acclaim PepMap RSLC column (75 $\mu \mathrm{m}$ i.d., length $500 \mathrm{~mm}, \mathrm{C} 18$, particle size $2 \mu \mathrm{m}$, pore size $100 \AA)$. Tryptic peptides were separated by a linear gradient of mobile phase $\mathrm{B}(\mathrm{B}=$ $80 \%(v / v)$ acetonitrile $(\mathrm{ACN}), 0.08 \%(v / v)$ formic acid $(\mathrm{FA})$ in water) and $\mathrm{A}(\mathrm{A}=0.1 \%(v / v)$ FA in water) as follows: $2 \%$ B over $4 \mathrm{~min}, 2-40 \%$ B over $64 \mathrm{~min}, 40-98 \%$ B over $2 \mathrm{~min}$. The flow rate was 300 $\mathrm{nl} / \mathrm{min}$. Tryptic peptides eluting from the column were injected into an Orbitrap Elite (Thermo Fisher Scientific, USA) operating in Top20 data-dependent acquisition mode. Scanning was set to $400-2000$ $\mathrm{m} / \mathrm{z}$ performed at 120000 resolution. The AGC target was $1 \times 10^{6}$ with a $200 \mathrm{~ms}$ injection time and twenty data-dependent MS2 scans (1 microscan, 10 ms injection time and 10000 AGC).

\section{Database searching and analysis}

The SILAC data were processed using Proteome Discoverer 1.4 (Thermo Fisher Scientific, USA) and the Mascot search engine with the following search settings: a human database, Swiss-Prot (April 2016); enzyme- trypsin; 2 missed cleavage sites; a precursor mass tolerance of $10 \mathrm{ppm}$; a fragment mass tolerance of $0.6 \mathrm{Da}$; modification included: carbamidomethyl [C], oxidation [M], acetyl [protein N-terminus]. The search results were used to generate the final report with a $1 \%$ FDR on both PSM and peptide groups. SILAC labels of R6 and $\mathrm{K} 6$ were chosen for heavy and R0 and $\mathrm{K} 0$ for light. The relative quantification value was represented as heavy/light ratio (Table S1).

\section{Data availability}

The mass spectrometry proteomics data have been deposited to the ProteomeXchange Consortium via the PRIDE partner repository with the dataset identifier PXD030540, Username: reviewer_pxd030540@ebi.ac.uk, Password: jM0wyPd7. The entire set of RNA seq files have been deposited to the datadryad.org with DOI https://doi.org/10.5061/dryad.c59zw3r92.

\section{Results}


IFITMs are IFN-stimulated molecules involved in human cancer development, including cervical carcinogenesis (Pan et al., 2010). In addition, gene expression of cervical cancer specimens reveals an inverse correlation between IFN $\gamma$ and lymph node metastases (Kim et al., 2007). We engineered a cell model to study the role of IFITMs in this type of cancer; SiHa cells originating from squamous cell carcinoma of cervix express IFITM1 and IFITM3 at detectable endogenous levels with a higher expression upon IFN $\gamma$ stimulation (SI Appendix, Fig.1C). As IFITM2 protein was detected neither at endogenous level nor after IFN $\gamma$ stimulation in the parental wt-SiHa cells (SI Appendix, Fig. S1D), we genetically engineered IFITM1 and IFITM3 knockout cell line (hereafter referred to as IFITM1/IFITM3 null) by using CRISPR/Cas9 technology (SI Appendix, Fig. S1B). The immune-related IFITM1/2/3 proteins have conserved amino acid sequences and form homo- and hetero-oligomers (Siegrist, Ebeling and Certa, 2011; Winkler et al., 2019) suggesting that they cooperate together. Thus, to rule out any possible functional redundancy of IFITM1 and IFITM3, here, we use the IFITM1/IFITM3-knockout cells. Hence, the sgRNA was designed to introduce indels into the target IFITM sequences flanking the first exon for IFITM1 and IFITM3 genes to produce aberrant or truncated products (SI Appendix, Fig. S1A). After puromycin selection, individual clones were screened by immunoblotting (data not shown). A representative IFITM1/IFITM3 null clone showed IFITM1/3 protein expression diminished under the level of detection by Western blot (SI Appendix, Fig. S1C) and immunofluorescence (SI Appendix, Fig. S1E and F). More details on the design and screen of this cell model can be found in our previous publication (Gómez-Herranz et al., 2019).

Interaction of IFITM1 protein with the cytoplasmic translation factor protein SRSF1

IFITM1 is the main IFITM family member reported in tumor progression and poor prognosis for many human cancer types (Györffy et al., 2008b; Seyfried et al., 2008; Weichselbaum et al., 2008; Yu, Xie, Ng, Lum, M. Y. Cai, et al., 2015; Borg et al., 2016b; Ogony et al., 2016; Sari, Y. G. Yang, et al., 2016). Since IFITM interactome is not well defined, we asked whether new binding partners can emerge by employing Stable Isotope Labeling with Amino Acids in Cell Culture (SILAC) coupled to mass spectrometry (MS). The full-length IFITM1 gene was cloned into an SBP-tagged expression vector (Keefe et al., 2001) to allow for its affinity capture from crude lysates after transfection (SI Appendix, Fig. S2A). The affinity-purification protocol using streptavidin-beads was designed to capture SBP-IFITM1 and associated proteins. Cells were isotopically labeled using SILAC RPMI media containing $13 \mathrm{C}$ labeled arginine and lysine amino acids (R6K6), while the SBP empty-vector used as a negative control was expressed in cells containing unlabeled amino acids.

Under these conditions, SBP-IFITM1 protein was detected in the affinity capture from cells grown in heavy media, at both 24 and $48 \mathrm{~h}$ after transfection (SI Appendix, Fig. S2B, lanes 4 and 8 ) and, more importantly, SBP-IFITM1 peptides were dominantly identified after MS analysis (SI Appendix, Fig. S2C and Table S1). This internal control highlights that the methodology is able to enrich and identify the IFITM1 bait protein.

We focused on the common interacting proteins detected in the SBP-IFITM1 purification between these two time points. The most common targets were the splicing regulatory factors within the SRSF superfamily of serine-arginine-rich splicing factors; SRSF1, SRSF2, SRSF3, SRSF6, and

384 U2AF1 (SI Appendix, Fig. S2D; tryptic peptides are highlighted). Interestingly, one of the tryptic peptides derived from the SRSF1 isoform ASF-1, located in the alternatively spliced C-terminus 
characteristic for the cytosolic form that regulates protein translation on the ribosome (Maslon et al., 2014) (SI Appendix, Fig. S2D; SRSF1 tryptic peptide is underlined in red).

SRSF1 is the archetype component of the SR family of splicing factors (Zheng et al., 2020). Thus, the endogenous IFITM1 and SRSF1 co-association was further validated by proximity ligation assay (PLA), which can detect two endogenous protein-protein interactions in situ (Weibrecht et al., 2010), not relying on the expression of exogenous vector constructs. In this case, IFITM1 and IFITM3 were simultaneously detected to capture all IFITM endogenous interaction with SRSF1. A basal level of IFITM1/IFITM3-SRSF1 foci can be observed in non-stimulated wt-SiHa cells (Fig 1C vs 1A or 1B; quantified in 1I). The stimulation with IFN $\gamma$ for $24 \mathrm{~h}$ elevated the number of foci that predominate in the cytoplasm (Fig 1D vs 1C; quantified in 1I). The cytoplasmic localization of the majority of IFITM1/IFITM3:SRSF1 foci is consistent with the tryptic peptides for the cytoplasmic isoform SRSF1 detected in the affinity capture (SI Appendix, Fig. S2D; SRSF1 and Table S1).

As a control for specificity, the IFITM1/IFITM3 null cells did not exhibit IFITM1/IFITM3SRSF1 foci, not even after IFN $\gamma$ stimulation (Fig 1E-H; quantified in J). SRSF1 protein itself is not induced by IFN $\gamma$ treatment (Fig 1K), nor is SRSF1 depleted in the IFITM1/IFITM3 null cells (Fig 1K). These data indicate that the IFITM1/3 proteins themselves are predominantly responsible for the IFN $\gamma$ dependent induction of the SRSF1-IFITM1/IFITM3 foci (Fig 1D). The results suggest that the SBP-IFITM1 pull-down (SI Appendix, Fig. S2) captures authentically co-localizing IFITM1:SRSF1 complexes.

Interaction of IFITM1/3 with HLA-B RNA.

In our previous report, we described that endogenous HLA-B is deficiently expressed in IFN $\gamma$-stimulated cells lacking IFITM1/3 expression (Gómez-Herranz et al., 2019). In addition, the proposed SRSF1 interacting protein (SI Appendix, Fig. S2) is involved in RNA binding and transport (39). Then, we asked whether IFITM1/3 associate with mRNA in vivo. With this purpose, we examined the interaction between IFITM1/3 with HLA-B RNA as a potential mechanism to account for IFITM1/3-dependent HLA-B protein synthesis in response to IFN $\gamma$. Protein-RNA proximity ligations (rISH-PLA) (Roussis, Myers and Scarlett, 2017) was used to measure IFITM1 protein-HLAB RNA interactions. The IFITMs and HLA-B are ISG genes but the IFN $\gamma$-induced expression of HLAB is impaired in the absence of IFITM1/3 expression (Gómez-Herranz et al., 2019). Taking this into account, wt-SiHa cells and IFITM1/IFITM3 null cells were non-stimulated and IFN $\gamma$-stimulated for $24 \mathrm{~h}$ (Fig 2). Cells were processed as indicated in the methods and incubated with antibodies to IFITM1/3 and biotinylated probe designed to bind specifically the HLA-B mRNA.

FITC images identify the protein-RNA association foci (green) and DAPI was used for nuclear staining (blue). Cells were incubated as negative controls (Fig 2A-C and F-H); without the RNA probe (Fig 2A and F), using primary antibodies only (Fig 2B and G), or secondary antibodies only (Fig 2C and H). Cells were incubated with both IFITM1/IFITM3 and biotin antibodies to define protein-RNA foci in non-stimulated cells (Fig 2D and I) or IFN $\gamma$-stimulated cells (Fig 2E and J). Endogenous interactions between HLA-B mRNA and IFITM1/3 proteins are shown in wt-SiHa cells (Fig 2A-E) and barely any interaction was observed in IFITM1/IFITM3 null cells (Fig 2F-J). Representative quantification of the protein-RNA interaction foci per cell in presence or absence of IFN $\gamma$ stimulation in wt-SiHa cells (Fig 2K) and IFITM1/IFITM3 null cells (Fig 2L). Compiling both 
with SRSF1 protein and HLA-B RNA. Bringing all together, these results start explaining why HLAB protein synthesis is attenuated in the IFITM1/IFITM3 cells (Gómez-Herranz et al., 2019).

Transcriptomic analysis of the IFN $\gamma$ response in wt-SiHA and an IFITM1/IFITM3 null cells

Next, we asked whether attenuated HLA-B protein synthesis in the IFN $\gamma$-stimulated IFITM1/IFITM3 null cells (Gómez-Herranz et al., 2019) was related to reduced mRNA levels. This suggests that the dominant mechanism for IFITM1/3 protein signaling was transcription-dependent mechanisms. To address this question, a targeted, quantitative RT-PCR assay with biological triplicate samples from wt-SiHa and IFITM1/IFITM3 null cells non-stimulated or IFN $\gamma$-stimulated were measured, each in technical triplicate (SI Appendix, Fig. S3 I-IV-V). In addition to the HLA-B transcript, we also included additional IFN $\gamma$ stimulated genes as controls; STAT1, B2M, and IRF1; further, we validate the IFITM1/3 knockout cells; IFITM1 and IFITM3. Of note, STAT1, B2M, IFITM1 and HLA-B are IRDS genes.

The positive controls highlight equivalent mRNA levels observed upon IFN $\gamma$ induction of STAT1 (master signal transducer of the IFN $\gamma$ pathway) and B2M (MHC class I subunit) in both wtSiHa and IFITM1/IFITM3 null cells (Fig 3A I and II). This is consistent with our previous data, where we observed IFITM1/IFITM3-independent synthesis of STAT1 and B2M proteins using pulse-SILAC mass-spectrometry (Gómez-Herranz et al., 2019). In addition, IRF1 (transcriptional activator of the secondary ISG response in the IFN $\gamma$ pathway) was shown to partially attenuated in its synthesis in IFN $\gamma$-stimulated IFITM1/IFITM3 null cells using pulse-SILAC mass spectrometry (Gómez-Herranz et al., 2019); its mRNA levels are also equivalently induced by IFN $\gamma$ in both cell lines (Fig 3A V). Moreover, there is a reduction of both IFITM1 and IFITM3 mRNA abundance in IFN $\gamma$-stimulated IFITM1/IFITM3 null cells compared to wt-SiHa cells (Fig 3A III and 3 IV, respectively). These data might be expected if gene editing creates indels that result in stop codon mutations which cause mRNA degradation by NMD (Tuladhar et al., 2019).

Although HLA-B protein synthesis was not detected after IFN $\gamma$ stimulation in an IFITM1/IFITM3 null cells using pulse-SILAC mass spectrometry (Gómez-Herranz et al., 2019), there was an equivalent 100-250 fold increased relative levels of HLA-B mRNA in both the wt-SiHa cells and IFITM1/IFITM3 null cells (Fig 3A VI). This later result suggests that a transcriptionindependent mechanism is driving the reduced synthesis of HLA-B proteins after IFN $\gamma$ stimulation in IFITM1/IFITM3 null cells. Since HLA-B mRNA are similarly induced by IFN $\gamma$ in the IFITM1/IFITM3 null cells compared to wt-SiHA cells (Fig 3A VI), we next focused on understanding what might be linked to defects in protein synthesis in the IFITM1/IFITM3 null cells.

After these preliminary results, using the same RNA preparations used for RT-PCR analysis (Fig 3A), we performed global gene expression analysis by RNA-seq (Fig 3B) to investigate whether lack of IFITM1/3 expression, overall, changes other mRNA transcript products. Three biological replicates of wt-SiHa cells and the isogenic IFITM1/IFITM3 null cells were either left untreated (control) or IFN $\gamma$-stimulated for $24 \mathrm{~h}$ (SI Appendix, Fig. S3 I). Then, RNA from three biological replicates (non-stimulated or IFN $\gamma$-stimulated cells) was pooled, extracted, and processed by next generation RNA sequencing of polyA+ enriched RNA (SI Appendix, Fig. S3 II). The RNAseq data was annotated using CLC Genomics Workbench (12.0) (SI Appendix, Fig. S3 III and Table S2). 
protein expression does not decrease these transcripts (Fig 3B IV; highlighted in red). In addition to these classic IFN $\gamma$-inducible genes, other highly-induced transcripts after IFN $\gamma$ treatment are also revealed to be IFITM1/IFITM3-independent; these include HLA-DRB1, HLA-DRA, CXCL10 and GBP5 (Fig 3 I and IV, highlighted in black). These genes are related to tumor immunity or pathogen restriction (Mach et al., 1996; Soejima and Rollins, 2001; Feng et al., 2017). Nonetheless, globally, no major differences were observed in the total amount of transcripts in the cells lacking of IFITM1/3 expression compared to wt-SiHa cells (Fig 3B).

By comparing the mRNA ratio in wt-SiHa cells to IFITM1/IFITM3 null cells, the dominant suppressed gene detected was IFITM1 (Fig 3B II and III; highlighted in red). This is consistent with; IFITM1 being a dominant interferon-inducible target and IFITM1 gene mutation through guide RNA editing (as described in (Gómez-Herranz et al., 2019)) reduces the basal levels of the IFITM1 mRNA.

Furthermore, we focused on the mRNA abundance of the 31 genes composing the IRDS cluster. The HLA-B is an IRDS gene whose expression seems to be mediated by IFITM1/3; therefore, we investigated whether other transcripts originated from the IRDS genes may be affected. IRDS genes derived from Table S2 are a subset of IFN responsive genes linked to chemo-radiation resistance that include IFITM1 (but not IFITM3) and HLA-B (Erdal et al., 2017). In this regard, a heat map quantifying the expression of the IRDS genes are highlighted in SI Appendix, Fig. S4) . Overall, there is a substantial induction of IRDS genes after IFN $\gamma$ stimulation in both, the wt-SiHa cells and IFITM1/IFITM3 null cells (SI Appendix, Fig. S4).

Reduction in 80 S ribosomal RNA levels in the IFITM1/IFITM3 null cells using sucrose gradient sedimentation

Inconsistent with the transcriptomic analysis results, we aimed to investigate whether IFITM1/3 proteins can modulate HLA-B expression by other mechanisms not involving cellular transcription. We previously have shown that HLA-B interacts with IFITM1/3 (Gómez-Herranz et al., 2019) and, in this report, we have identified a new interacting partner for IFITM1, SRSF1, which interestingly mediates in the translation regulation (39). Taking all together, we investigate whether IFITM1/3 proteins may modulate HLA-B expression through intervention in the translational process.

In the attempt to study the relation of IFITM1/3 with HLA-B protein translation, we first asked whether IFITM1/3 proteins are present in the ribosome by studying their potential interaction with RPL7a protein, a ribosome-specific protein used as a subcellular marker. RPL7a is a component of the $60 \mathrm{~S}$ ribosomal (Robledo et al., 2008) that associates with the endoplasmic reticulum (Wu, Liu and Lin, 2007). By performing a PLA, there is a significantly increased protein-protein association of IFITM1/IFITM3:RPL7a after IFN $\gamma$-stimulation in the cytosol compared to non-stimulated wt-SiHa cells (Fig 4C vs D and I). In contrast, there is almost no detectable signal in IFN $\gamma$-stimulated IFITM1/IFITM3 null cells (Fig 4H and J). It is worth mentioning that IFITM1/IFITM3 proteins accumulate perinuclearly upon IFN $\gamma$ stimulation (SI Appendix, Fig. S1E, arrowhead in merge composition with IFN $\gamma$-stimulated in wt-SiHa cells), which is consistent with a possible ribosomal localization after the activation of the IFNg signaling.

511 Given that IFITM1 can regulate HIV mRNA translation (Lee et al., 2018), we set out to 512 determine whether defects in ribosomal integrity was linked to defects in HLA-B protein synthesis (Gómez-Herranz et al., 2019) in the IFITM1/IFITM3 null cells. An analysis of the ribosomal profile 
integrity. Then, cell lysates from IFN $\gamma$-stimulated cells were subjected to sucrose gradient sedimentation under conditions that maintain ribosome integrity (Fig 5). Immunoblots of the polysomal fractions indicated that IFITM1/3 proteins can be detected in the $40 \mathrm{~S}, 60 \mathrm{~S}$, and $80 \mathrm{~S}$ fractions from wt-SiHa cells but not from the IFITM1/IFITM3 null cells (Fig 5B).

The representative A254 nm peaks of 40S, 60S, 80S and polysomal fractions is depicted in Fig 5A. Interestingly, the A254 absorbance scan of the 80S subunit fraction in the IFITM1/IFITM3 null cells was reproducibly lower than in wt-SiHa cells in three independent biological replicates (Fig 5A, 5C, and 5D; quantified in 5E and SI Appendix, Fig. S5A-C). Remarkably, transient transfection of IFITM1 and IFITM3 genes for $24 \mathrm{~h}$ into the an IFITM1/IFITM3 null cells, in three independent biological replicates, can partially restore $80 \mathrm{~S}$ ribosomal RNA levels as defined by increase in A254 nm (SI Appendix, Fig. S5D-F). These data suggest a selective impairment in the RNA component of the $80 \mathrm{~S}$ ribosome in absence of IFITM1/3 expression. However, the defects observed in $80 \mathrm{~S}$ integrity are not an irreversible feature of the IFITM1/IFITM3 null cell line.

\section{Discussion}

Several studies have postulated that high expression of the IFN-stimulated IFITM1 and IFITM3 proteins can stimulate more aggressive growth of human cancers (Ogony et al., 2016; Yang et al., 2018; Lee et al., 2020; Zhu et al., 2020). In addition, IFITM1 is a component of the IRDS found upregulated during the development of radiation resistance (Weichselbaum et al., 2008). By contrast, IFITM1 activity is linked to growth suppression in cervical cancers (Yang et al., 2007; Zheng et al., 2017). In this regard, in our previous work, we identified a distinct subgroup of cervical cancer patients where IFITM1/IFITM3 proteins are highly expressed in cervical cancers. However, its expression is inversely correlated to the number of metastatic lymph nodes (Gómez-Herranz et al., 2019). With this premise, we aimed to understand why patients who are IFITM1/IFITM3 double negative are also susceptible to developing aggressive tumors.

To broaden the limited molecular understanding of IFITM1 and IFITM3 function(s), in our previous report, we developed a MS assay to determine whether IFITM1 and IFITM3 play a role in the response of cells to IFN-induced protein synthesis (Gómez-Herranz et al., 2019). As a result, we identified HLA-B, an MHC class I molecule, as one of the few dominant downstream effectors of IFITM1/3 (Gómez-Herranz et al., 2019). Moreover, a decreased expression of HLA-B on the cell surface in cells with complete loss of IFITM1/3 expression was observed. Taking all together, the data suggested that loss of IFITM1/3 expression would attenuate antigen presentation in vivo (GómezHerranz et al., 2019). However, in this current study, we are interested in which cellular process explains why HLA-B exhibits lowered synthesis in the IFITM1/IFITM3 null cells. With this, we could further comprehend other mechanisms by which the antigen presentation pathway is regulated.

To begin with, we start tackling this question by identifying new interacting partners for IFITM that could shed some light on which novel role IFITM1/3 proteins can be implicated. We identified multiple members of the SR family of splicing factors (SRSF1, SRSF2, SRSF3, SRSF6 and U2AF1) as novel candidates to associate with IFITM1 protein by employing affinity capture assay coupled to pulse-SILAC mass spectrometry (SI Appendix, Fig. S2). A Proximity ligation assay confirmed the association between IFITM1/3 and SRSF1 (Fig 1). However, immunoblot did not show major difference in the expression of SRSF1 in cells lacking of IFITM1/3 expression (Fig 1K). Interestingly, in addition to be implicated with the splicing machinery, the 5 splicing factors 
identified are implicated in the mRNA transport (Das and Krainer, 2014). SRSF2 is considered as nonnuclear to cytoplasmic shuttled protein, however, it has its C-terminal enriched in arginine and serine; these amino acid motifs are crucial for the nuclear exit of the mentioned slicing factors (SI Appendix, Fig. S2D; SRSF2). Thus, we study the possible implication of IFITM1/3 proteins regulating the transcript products. To address this possibility, the performed RNA expression analysis did not reveal a dominating defect in the HLA-B gene expression neither in the global transcript production by comparing IFITM1/IFITM3 null cell with wt-SiHa cells (Fig 3 and SI Appendix, Fig. S3 and Fig. S4). These data suggested that defects in HLA-B protein synthesis in cells lacking IFITM1/3 expression are not selectively due to suppression of IFN-stimulated gene induction even though IFITM1/3 associates with the HLA-B mRNA (Fig 2).

SRSF factors are implicating in guiding the mRNA products to the ribosome (Das and Krainer, 2014) and a ribosomal localization of IFITM1/3 proteins is also inferred due to the coassociation of RPL7a and IFITM1/3 proteins using proximity ligation assays (Fig 4). RPL7a is a component of the $60 \mathrm{~S}$ ribosomal subunit that contains nucleic acid-binding domains, and it is implicated in regulating the expression of mRNAs (Neumann et al., 1995; Neumann and Krawinkel, 573 1997).

Next, we interrogated whether IFITM1/3 could be mediating selectively the protein synthesis, more representative for HLA-B, by modulating their translation. To find some answers, we evaluated the ribosomal profile using ultracentrifugation sedimentation of cell lysates from IFN $\gamma$-stimulated wt-SiHa cells and IFITM1/IFITM3 null cells to isolate ribosomal constituents. Our results suggest a specific role for IFITM1/IFITM3 in regulating the integrity of $80 \mathrm{~S}$ ribosomal subunit, restored with the exogenous transient expression of IFITM1/3 (Fig 5 and SI Appendix, Fig. S5). During the course of our studies, it was shown that IFITM protein expression reduces HIV-1 viral protein synthesis by preferentially excluding viral mRNA transcripts from translation (Lee et al., 2018). This study supports our vision where a new exciting role for IFITM family members operating at the level of protein translation is emerging. Although we focused on the role of IFITM1/3 regulating HLA-B, there may be other cancer and virus originated proteins whose expression may be mediated by IFITM1/3.

Here, we are starting to reveal an alternative novel role for IFITM1/3 proteins that may help to understand the complicated mechanism by which MHC class I molecules are regulated. Further direction will address the question on how specifically IFITM1/3 mediates the HLA-B expression; whether is required to form the protein complexes guiding mRNA, guides the mRNA to the ribosome, excludes the mRNA loading into the ribosome or a combination of all.

However, our findings emphasize the importance of IFITM1/IFITM3 to mediate HLA-B protein expression through interactions with its mRNA. Such RNA-dependent effects on HLA-B synthesis might impact on the global number of neo-antigens presented to CD8+ T cells, otherwise promoting immune scape. From a cervical cancer perspective, MHC class I depletion is not correlated with HPV positive tissues (Connor and Stern, 1990; Cromme et al., 1993); it is suggested that these events are originated at different stages of cervical cancer progression. Independent studies have identified impaired MHC class I expression in cervical tumors (and other cancer types); particularly loss of MHC class I molecules occur in metastatic lesions compared to primary tumors (Torres et al., 1993; Honma et al., 1994), including chromosomal aberrations (Koopman et al., 2000). This is of 
regulate, at least partially, the expression of MHC class I proteins. Remarkably, several studies revealed HLA expression deficiencies in lymph node metastases compared to primary tumor

603 (Cromme et al., 1994; Ferns et al., 2016) which is consistent with the concept that lack of IFITM1/IFITM3 would lead to diminished HLA expression (Gómez-Herranz et al., 2019).

Supporting Information: This article contains SI Appendix; Fig. S1: Workflow for generating IFITM1/3-knockout SiHa cells using CRISPR/Cas9 gene editing technology, Fig. S2: Identification of IFITM1 interacting proteins, Fig S3: Workflow followed to analyze the transcriptome in wt-SiHa cells and IFITM1/IFITM3 null cells, Fig. S4: Heat map representation of the mRNA induction of the 31 IRDS genes, Fig. S5: Original scans for the mRNA trace after sucrose density gradient fractionation in six independent replicates, Table S1: List of proteins enriched in SBP-IFITM1 pull down, Table S2: Generation of RNA seq datasets from the indicated cell lines using CLCBio Genomics workbench

61312.0.

614 Acknowledgments: We would like to thank all past and current member of the laboratory for their contribution to scientific discussions and giving us so much support throughout all these years of research. A special thank you to Dr. Marta Nekulova for engineering the CRIPSR/Cas9 IFITM1/IFITM3 null cells and to Dr. Magadalena M. Maslon and Cáceres group for the help provided during polysome fractionation.

\section{References}

620 Alberts, D.S. et al. (2008) “Randomized phase 3 trial of interferon gamma-1b plus standard

621 carboplatin/paclitaxel versus carboplatin/paclitaxel alone for first-line treatment of advanced

622 ovarian and primary peritoneal carcinomas: results from a prospectively designed analysis of progression-free survival," Gynecologic oncology, 109(2), pp. 174-181.

624 doi:10.1016/J.YGYNO.2008.01.005.

Amini-Bavil-Olyaee, S. et al. (2013) “The antiviral effector IFITM3 disrupts intracellular cholesterol homeostasis to block viral entry," Cell Host and Microbe, 13(4), pp. 452-464. doi:10.1016/j.chom.2013.03.006.

628 Bailey, C.C. et al. (2014) "IFITM-Family Proteins: The Cell's First Line of Antiviral Defense," Annu. Rev. Virol., 1, pp. 261-283. doi:10.1146/annurev-virology-031413-085537.

630 Bekisz, J. et al. (2004) “Human Interferons Alpha, Beta and Omega," Growth Factors, 22(4), pp. 243631 251. doi:10.1080/08977190400000833.

632 Booy, S., Hofland, L. and van Eijck, C. (2015) "Potentials of interferon therapy in the treatment of

633 pancreatic cancer," Journal of interferon \& cytokine research : the official journal of the International

634 Society for Interferon and Cytokine Research, 35(5), pp. 327-339. doi:10.1089/JIR.2014.0157.

635 Borden, E.C.; et al. (2007) "Interferons at age 50: past, current and future impact on biomedicine,"

636 Nature Reviews: Drug Discovery, 6, pp. 975-990. doi:10.1038/nrd2422.

637 Borg, D. et al. (2016a) "Expression of IFITM1 as a prognostic biomarker in resected gastric and

638 esophageal adenocarcinoma.," Biomarker research, 4, p. 10. doi:10.1186/s40364-016-0064-5.

639 Borg, D. et al. (2016b) “Expression of IFITM1 as a prognostic biomarker in resected gastric and 640 esophageal adenocarcinoma," Biomarker research, 4(1). doi:10.1186/S40364-016-0064-5.

641 Bradford, M.M. (1976) "A rapid and sensitive method for the quantitation of microgram quantities 642 of protein utilizing the principle of protein-dye binding," Analytical biochemistry, 72(1-2), pp. 248643 254. doi:10.1006/ABIO.1976.9999. 

Virus, West Nile Virus, and Dengue Virus," Cell, 139(7), pp. 1243-1254. doi:10.1016/j.cell.2009.12.017. Budhwani, M., Mazzieri, R. and Dolcetti, R. (2018) “Plasticity of Type I Interferon-Mediated

648 Responses in Cancer Therapy: From Anti-tumor Immunity to Resistance," Frontiers in oncology, 649 8(AUG). doi:10.3389/FONC.2018.00322.

650 Cheon, H., Borden, E.C. and Stark, G.R. (2014) "Interferons and their stimulated genes in the tumor

651 microenvironment," Seminars in oncology [Preprint]. doi:10.1053/j.seminoncol.2014.02.002.

652 Connor, M.E. and Stern, P.L. (1990) “Loss of MHC class-I expression in cervical carcinomas,"

653 International journal of cancer, 46(6), pp. 1029-1034. doi:10.1002/IJC.2910460614.

654 Cromme, F. v. et al. (1993) "Analysis of MHC class I and II expression in relation to presence of HPV 655 genotypes in premalignant and malignant cervical lesions," British Journal of Cancer, 67(6), pp. 1372656 1380. doi:10.1038/bjc.1993.254.

657 Cromme, F. v. et al. (1994) "Loss of transporter protein, encoded by the TAP-1 gene, is highly 658 correlated with loss of HLA expression in cervical carcinomas," The Journal of experimental medicine, 659 179(1), pp. 335-340. doi:10.1084/JEM.179.1.335.

660 Darnell, J., Kerr, I. and Stark, G. (1994) "Jak-STAT pathways and transcriptional activation in 661 response," Science, 264(5164), pp. 1415-1421. doi:10.1126/science.8197455.

662 Das, S. and Krainer, A.R. (2014) "Emerging functions of SRSF1, splicing factor and oncoprotein, in

663 RNA metabolism and cancer," Molecular cancer research : MCR, 12(9), pp. 1195-1204.

664 doi:10.1158/1541-7786.MCR-14-0131.

665 Erdal, E. et al. (2017) "A prosurvival DNA damage-induced cytoplasmic interferon response is 666 mediated by end resection factors and is limited by Trex1," Genes $\mathcal{E}$ development, 31(4), pp. 353-369.

667 doi:10.1101/GAD.289769.116.

668 Fan, J. et al. (2008) “Gene-expression profiling in Chinese patients with colon cancer by coupling

669 experimental and bioinformatic genomewide gene-expression analyses: Identification and

670 validation of IFITM3 as a biomarker of early colon carcinogenesis," Cancer, 113(2), pp. 266-275.

671 doi:10.1002/cncr.23551.

672 Feng, J. et al. (2017) “Inducible GBP5 Mediates the Antiviral Response via Interferon-Related

673 Pathways during Influenza A Virus Infection," Journal of innate immunity, 9(4), pp. 419-435.

674 doi:10.1159/000460294.

675 Ferns, D.M. et al. (2016) “Classical and non-classical HLA class I aberrations in primary cervical

676 squamous- and adenocarcinomas and paired lymph node metastases," Journal for immunotherapy of 677 cancer, 4(1). doi:10.1186/S40425-016-0184-3.

678 Gómez-Herranz, M. et al. (2019) "The effects of IFITM1 and IFITM3 gene deletion on IFN $\gamma$

679 stimulated protein synthesis," Cellular signalling, 60, pp. 39-56. doi:10.1016/J.CELLSIG.2019.03.024.

680 Green, D.S. et al. (2016) "Monocyte and interferon based therapy for the treatment of ovarian

681 cancer," Cytokine \& growth factor reviews, 29, pp. 109-115. doi:10.1016/J.CYTOGFR.2016.02.006.

682 Györffy, B. et al. (2008a) "A snapshot of microarray-generated gene expression signatures associated 683 with ovarian carcinoma," International Journal of Gynecological Cancer, 18(6), pp. 1215-1233.

684 doi:10.1111/j.1525-1438.2007.01169.x. 
Györffy, B. et al. (2008b) "A snapshot of microarray-generated gene expression signatures

associated with ovarian carcinoma," International journal of gynecological cancer : official journal of the International Gynecological Cancer Society, 18(6), pp. 1215-1233. doi:10.1111/J.1525-1438.2007.01169.X. Honma, S. et al. (1994) "Biological-clinical significance of selective loss of HLA-class-I allelic product expression in squamous-cell carcinoma of the uterine cervix," International journal of cancer, 57(5), pp. 650-655. doi:10.1002/IJC.2910570507.

Ives, N.J. et al. (2017) “Adjuvant interferon- $\alpha$ for the treatment of high-risk melanoma: An individual patient data meta-analysis," European journal of cancer (Oxford, England: 1990), 82, pp. 171-183. doi:10.1016/J.EJCA.2017.06.006.

Jia, R. et al. (2015) “The C-Terminal Sequence of IFITM1 Regulates Its Anti-HIV-1 Activity," PLoS ONE, pp. 1-17. doi:10.1371/journal.pone.0118794.

Jorgovanovic, D. et al. (2020) "Roles of IFN- $\gamma$ in tumor progression and regression: a review," Biomarker research, 8(1). doi:10.1186/S40364-020-00228-X.

Keefe, A.D. et al. (2001) “One-step purification of recombinant proteins using a nanomolar-affinity streptavidin-binding peptide, the SBP-Tag," Protein expression and purification, 23(3), pp. 440-446. doi:10.1006/PREP.2001.1515.

Khodarev, N.N., Roizman, B. and Weichselbaum, R.R. (2012) “Molecular pathways: Interferon/Stat1 pathway: Role in the tumor resistance to genotoxic stress and aggressive growth," Clinical Cancer Research, 18(11), pp. 3015-3021. doi:10.1158/1078-0432.CCR-11-3225.

Kim, T.-J. et al. (2007) "Gene expression profiling for the prediction of lymph node metastasis in patients with cervical cancer," Cancer Science, 0(0), pp. 071106234520002-??? doi:10.1111/j.13497006.2007.00652.x.

Kolosenko, I. et al. (2015) “Cell crowding induces interferon regulatory factor 9, which confers resistance to chemotherapeutic drugs," International journal of cancer, 136(4), pp. E51-E61. doi:10.1002/IJC.29161.

van der Kooij, M.K. et al. (2020) "Phase I/II study protocol to assess safety and efficacy of adoptive cell therapy with anti-PD-1 plus low-dose pegylated-interferon-alpha in patients with metastatic melanoma refractory to standard of care treatments: the ACTME trial," BMJ open, 10(11). doi:10.1136/BMJOPEN-2020-044036.

Koopman, L.A. et al. (2000) "Multiple genetic alterations cause frequent and heterogeneous human histocompatibility leukocyte antigen class I loss in cervical cancer," The Journal of experimental medicine, 191(6), pp. 961-975. doi:10.1084/JEM.191.6.961.

Lee, J. et al. (2020) "IFITM3 functions as a PIP3 scaffold to amplify PI3K signalling in B cells," Nature, 588(7838), pp. 491-497. doi:10.1038/S41586-020-2884-6.

Lee, W.Y.J. et al. (2018) "IFITM proteins inhibit HIV-1 protein synthesis," Scientific Reports, 8(1), pp. 1-15. doi:10.1038/s41598-018-32785-5.

Liu, Y. et al. (2020) "High IFITM3 expression predicts adverse prognosis in acute myeloid leukemia," Cancer Gene Therapy, 27(1-2), pp. 38-44. doi:10.1038/s41417-019-0093-y. Mach, B. et al. (1996) "Regulation of MHC class II genes: lessons from a disease," Annual review of immunology, 14, pp. 301-331. doi:10.1146/ANNUREV.IMMUNOL.14.1.301.

Marth, C. et al. (2006) "Interferon-gamma in combination with carboplatin and paclitaxel as a safe and effective first-line treatment option for advanced ovarian cancer: results of a phase I/II study," 
International journal of gynecological cancer, 16(4), pp. 1522-1528. doi:10.1111/J.15251438.2006.00622.X.

729 Maslon, M.M. et al. (2014) "The translational landscape of the splicing factor SRSF1 and its role in mitosis," eLife, 3(3). doi:10.7554/ELIFE.02028. Narayana, S.K. et al. (2015) “The Interferon-induced Transmembrane Proteins, IFITM1, IFITM2, and IFITM3 Inhibit Hepatitis C Virus Entry," The Journal of biological chemistry, 290(43), pp. 25946-25959. doi:10.1074/JBC.M115.657346.

734 Neumann, F. et al. (1995) “Human ribosomal protein L7 inhibits cell-free translation in reticulocyte lysates and affects the expression of nuclear proteins upon stable transfection into Jurkat T-

736 lymphoma cells," Nucleic acids research, 23(2), pp. 195-202. doi:10.1093/NAR/23.2.195.

737 Neumann, F. and Krawinkel, U. (1997) “Constitutive expression of human ribosomal protein L7 738 arrests the cell cycle in G1 and induces apoptosis in Jurkat T-lymphoma cells," Experimental cell 739 research, 230(2), pp. 252-261. doi:10.1006/EXCR.1996.3417.

740 Ogony, J. et al. (2016) “Interferon-induced transmembrane protein 1 (IFITM1) overexpression

741 enhances the aggressive phenotype of SUM149 inflammatory breast cancer cells in a signal

742 transducer and activator of transcription 2 (STAT2)-dependent manner.," Breast cancer research :

$743 \quad B C R, 18(1)$, p. 25. doi:10.1186/s13058-016-0683-7.

744 Pan, Z. et al. (2010) “Differential gene expression identified in Uigur women cervical squamous cell carcinoma by suppression subtractive hybridization," pp. 2-7. doi:10.4149/neo.

746 Parker, B.S., Rautela, J. and Hertzog, P.J. (2016) “Antitumour actions of interferons: implications for cancer therapy," Nature reviews. Cancer, 16(3), pp. 131-144. doi:10.1038/NRC.2016.14.

748 Platanias, L.C. (2005) "Mechanisms of type-I- and type-II-interferon-mediated signalling," Nature Reviews Immunology, 5(5), pp. 375-386. doi:10.1038/nri1604.

750 Pujade-Lauraine, E. et al. (1996) "Intraperitoneal recombinant interferon gamma in ovarian cancer 751 patients with residual disease at second-look laparotomy," Journal of clinical oncology : official journal

752 of the American Society of Clinical Oncology, 14(2), pp. 343-350. doi:10.1200/JCO.1996.14.2.343.

753 Robichaud, N. et al. (2019) "Translational Control in Cancer," Cold Spring Harbor perspectives in 754 biology, 11(7). doi:10.1101/CSHPERSPECT.A032896.

755 Robledo, S. et al. (2008) "The role of human ribosomal proteins in the maturation of rRNA and 756 ribosome production," RNA (New York, N.Y.), 14(9), pp. 1918-1929. doi:10.1261/RNA.1132008. 757 Roussis, I.M., Myers, F.A. and Scarlett, G.P. (2017) “RNA Whole-Mount In Situ Hybridization 758 Proximity Ligation Assay (rISH-PLA), an Assay for Detecting RNA-Protein Complexes in Intact 759 Cells," Current protocols in cell biology, 74, pp. 17.20.1-17.20.10. doi:10.1002/CPCB.13.

760 Sanford, J.R. et al. (2004) “A novel role for shuttling SR proteins in mRNA translation," Genes $\mathcal{E}$ 761 development, 18(7), pp. 755-768. doi:10.1101/GAD.286404.

762 Sari, I.N., Yang, Y.-G., et al. (2016) Interferon-induced transmembrane protein 1 (IFITM1) is required for 763 the progression of colorectal cancer, Oncotarget. Available at: www.impactjournals.com/oncotarget.

764 Sari, I.N., Yang, Y.G., et al. (2016) "Interferon-induced transmembrane protein 1 (IFITM1) is

765 required for the progression of colorectal cancer," Oncotarget, 7(52), pp. 86039-86050.

766 doi:10.18632/ONCOTARGET.13325.

767 Seyfried, N.T. et al. (2008) “Up-regulation of NG2 proteoglycan and interferon-induced 768 transmembrane proteins 1 and 3 in mouse astrocytoma: A membrane proteomics approach," Cancer 769 Letters, 263(2), pp. 243-252. doi:10.1016/j.canlet.2008.01.007. 
Siegrist, F., Ebeling, M. and Certa, U. (2011) “The small interferon-induced transmembrane genes and proteins," Journal of interferon \& cytokine research : the official journal of the International Society for Interferon and Cytokine Research, 31(1), pp. 183-197. doi:10.1089/JIR.2010.0112. Soejima, K. and Rollins, B.J. (2001) “A functional IFN-gamma-inducible protein-10/CXCL10-specific receptor expressed by epithelial and endothelial cells that is neither CXCR3 nor glycosaminoglycan," Journal of immunology (Baltimore, Md. : 1950), 167(11), pp. 6576-6582. doi:10.4049/JIMMUNOL.167.11.6576. Tamura, K. et al. (1987) "Recombinant interferon beta and gamma in the treatment of adult T-cell leukemia," Cancer, 59(6), pp. 1059-1062. doi:10.1002/1097-0142(19870315)59:6<1059::aidcncr2820590602>3.0.co;2-m.

780 Torres, L.M. et al. (1993) “HLA class I expression and HPV-16 sequences in premalignant and

781 malignant lesions of the cervix," Tissue antigens, 41(2), pp. 65-71. doi:10.1111/J.1399-

782 0039.1993.ТВ01981.X.

783 Tuladhar, R. et al. (2019) “CRISPR-Cas9-based mutagenesis frequently provokes on-target mRNA

784 misregulation," Nature communications, 10(1). doi:10.1038/S41467-019-12028-5.

785 Wallace, T.A., Martin, D.N. and Ambs, S. (2011) "Interactions among genes, tumor biology and the environment in cancer health disparities: Examining the evidence on a national and global scale,"

787 Carcinogenesis, 32(8), pp. 1107-1121. doi:10.1093/carcin/bgr066.

788 Wang, B.X., Rahbar, R. and Fish, E.N. (2011) “Interferon: current status and future prospects in

789 cancer therapy," Journal of interferon \& cytokine research : the official journal of the International Society for Interferon and Cytokine Research, 31(7), pp. 545-552. doi:10.1089/JIR.2010.0158.

791 Wang, H. et al. (2020) "IFITM3/STAT3 axis promotes glioma cells invasion and is modulated by TGF- $\beta, "$ Molecular Biology Reports, 47(1), pp. 433-441. doi:10.1007/s11033-019-05146-2.

793 Weibrecht, I. et al. (2010) "Proximity ligation assays: a recent addition to the proteomics toolbox,"

794 Expert review of proteomics, 7(3), pp. 401-409. doi:10.1586/EPR.10.10.

795 Weichselbaum, R.R. et al. (2008) "An interferon-related gene signature for DNA damage resistance 796 is a predictive marker for chemotherapy and radiation for breast cancer," Proceedings of the National 797 Academy of Sciences, 105(47), pp. 18490-18495. doi:10.1073/pnas.0809242105.

798 Weston, S. et al. (2014) “A Membrane Topology Model for Human Interferon Inducible

799 Transmembrane Protein 1," PLoS ONE [Preprint]. doi:10.1371/journal.pone.0104341.

800 Williams, B. (1991) "Transcriptional regulation of interferon-stimulated genes," European journal of 801 biochemistry, 200(1), pp. 1-11. doi:10.1111/J.1432-1033.1991.TB21041.X.

802 Windbichler, G.H. et al. (2000) "Interferon-gamma in the first-line therapy of ovarian cancer: a

803 randomized phase III trial," British journal of cancer, 82(6), pp. 1138-1144.

804 doi:10.1054/BJOC.1999.1053.

805 Winkler, M. et al. (2019) "Analysis of IFITM-IFITM Interactions by a Flow Cytometry-Based FRET 806 Assay," International journal of molecular sciences, 20(16). doi:10.3390/IJMS20163859.

807 Wiśniewski, J.R. et al. (2009) “Universal sample preparation method for proteome analysis," Nature 808 methods, 6(5), pp. 359-362. doi:10.1038/NMETH.1322.

809 Wu, T.H. et al. (2011) "Progression of cancer from indolent to aggressive despite antigen retention 810 and increased expression of interferon-gamma inducible genes - PubMed," Cancer Immunology, 811 11(2). 
Wu, W.C., Liu, H.W. and Lin, A. (2007) “Human ribosomal protein L7 displays an ER binding property and is involved in ribosome-ER association," FEBS letters, 581(4), pp. 651-657.

814 doi:10.1016/J.FEBSLET.2007.01.023.

$815 \mathrm{Xu}, \mathrm{Y}$. and Ruggero, D. (2020) "The Role of Translation Control in Tumorigenesis and Its

816 Therapeutic Implications," https://doi.org/10.1146/annurev-cancerbio-030419-033420, 4, pp. 437-457.

817 doi:10.1146/ANNUREV-CANCERBIO-030419-033420.

818 Xu, Y., Yang, G. and Hu, G. (2009) “Binding of IFITM1 enhances the inhibiting effect of caveolin-1

819 on ERK activation," Acta biochimica et biophysica Sinica, 41(6), pp. 488-494.

820 doi:10.1093/ABBS/GMP034.

821 Yang, G. et al. (2007) "IFITM1 plays an essential role in the antiproliferative action of interferon-

822 gamma," Oncogene, 26(4), pp. 594-603. doi:10.1038/SJ.ONC.1209807.

823 Yang, J. et al. (2018) "Combination of IFITM1 knockdown and radiotherapy inhibits the growth of

824 oral cancer," Cancer science, 109(10), pp. 3115-3128. doi:10.1111/CAS.13640.

825 Yu, F., Xie, D., Ng, S.S., Lum, C.T., Cai, M.-Y., et al. (2015) “IFITM1 promotes the metastasis of

826 human colorectal cancer via CAV-1," Cancer Letters, 368(1), pp. 135-143.

827 doi:10.1016/j.canlet.2015.07.034.

828 Yu, F., Xie, D., Ng, S.S., Lum, C.T., Cai, M.Y., et al. (2015) “IFITM1 promotes the metastasis of

829 human colorectal cancer via CAV-1," Cancer letters, 368(1), pp. 135-143.

830 doi:10.1016/J.CANLET.2015.07.034.

831 Zheng, W. et al. (2017) "Down-regulation of IFITM1 and its growth inhibitory role in cervical 832 squamous cell carcinoma," Cancer cell international, 17(1). doi:10.1186/S12935-017-0456-0.

833 Zheng, X. et al. (2020) "Serine/arginine-rich splicing factors: the bridge linking alternative splicing 834 and cancer," International journal of biological sciences, 16(13), pp. 2442-2453. doi:10.7150/IJBS.46751. 835 Zhu, X. et al. (2020) "miR-152-3p Affects the Progression of Colon Cancer via the KLF4/IFITM3 836 Axis," Computational and mathematical methods in medicine, 2020. doi:10.1155/2020/8209504. 


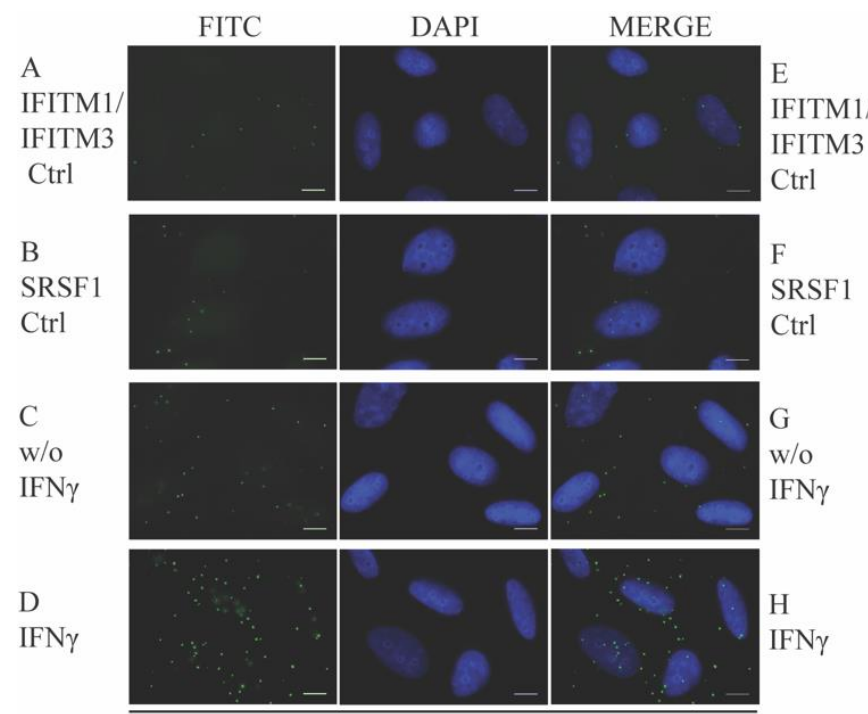

wt-SiHa
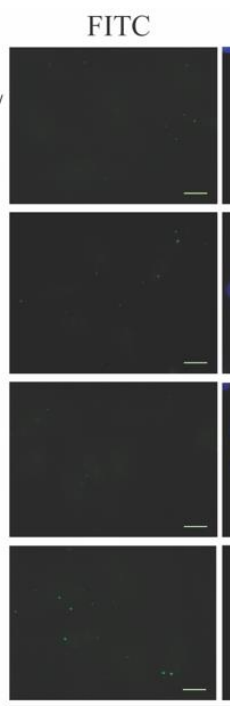

IFITM1/IFITM3 null

DAPI
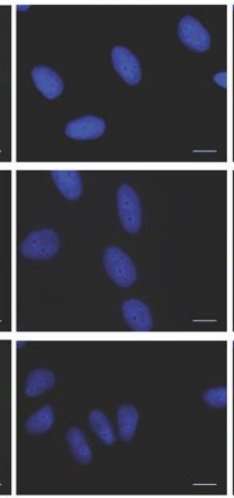

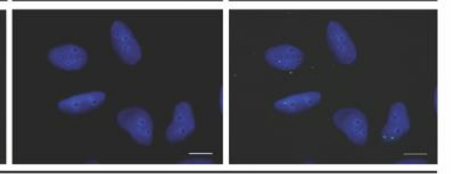

wt-SiHa IFITM1/

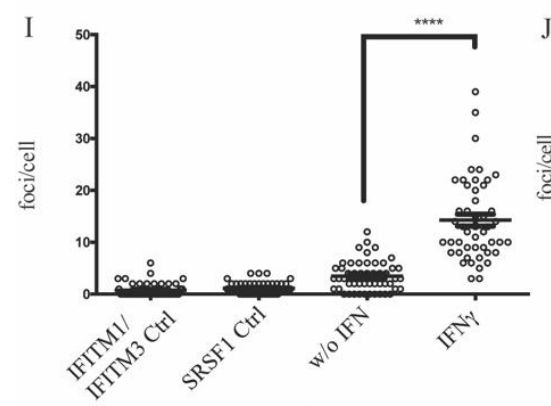

wt-SiHa

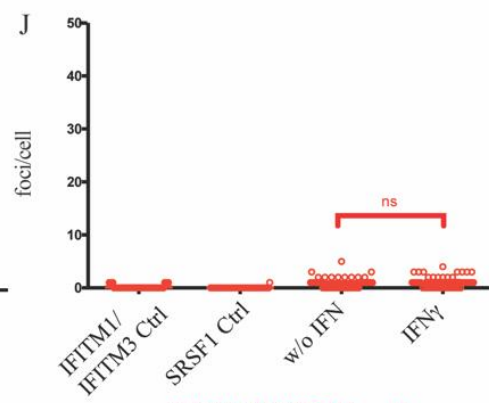

IFITM1/IFITM3 null

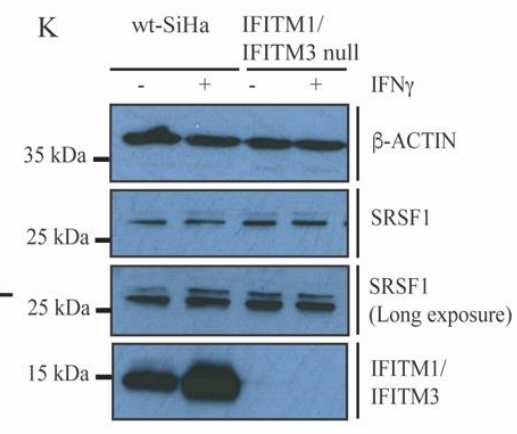

Figure 1. Evaluation of the IFITM1/IFITM3:SRSF1 protein-protein expression and interaction in situ after stimulation with IFN $\gamma$. Proximity ligation assays were used to study the endogenous interaction between SRSF1 and IFITM1/3 proteins in wt-SiHa (A-D) and IFITM1/IFITM3 null cells (E-H). FITC images identify the proteinprotein association foci (depicted in green) and DAPI was used for nuclear staining (depicted in blue). (A-B and E-F) Cells were incubated as negative controls using IFITM1/IFITM3 or SRSF1 antibodies only. (C and G) Cells were incubated with both IFITM1/IFITM3 and SRSF1 antibodies to define protein-protein foci in non-stimulated cells. (D and H) Cells were incubated with both IFITM1 and SRSF1 antibodies to define protein-protein foci in IFN $\gamma$-stimulated cells. Representative quantification of the protein-protein interaction foci per cell in presence or absence of IFN stimulation in wt-SiHa cells (I) and IFITM1/IFITM3 null cells (J). At least 50 cells were counted in each condition. Statistical study was performed with one-way ANOVA and Bonferroni correction $\left({ }^{* * * *} \mathrm{p}<\right.$ 0.0001; ns, not significant). $\mathrm{n}=3$. Scale bar: $10 \mu \mathrm{m}$. (K) Immunoblots examining the endogenous levels of SRSF1 protein in non-stimulated or IFN $\gamma$-stimulated wt-SiHa cells or IFITM1/IFITM3 null cells. 


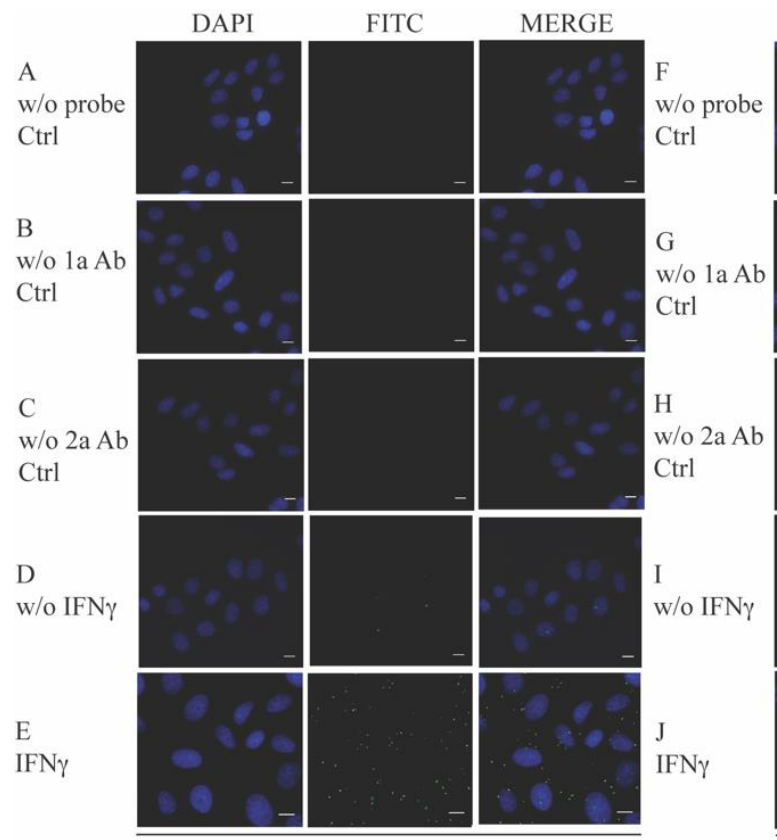

wt-SiHa

$\mathrm{K}$

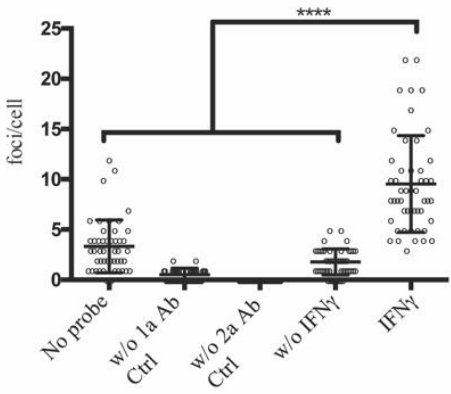

wt-SiHa

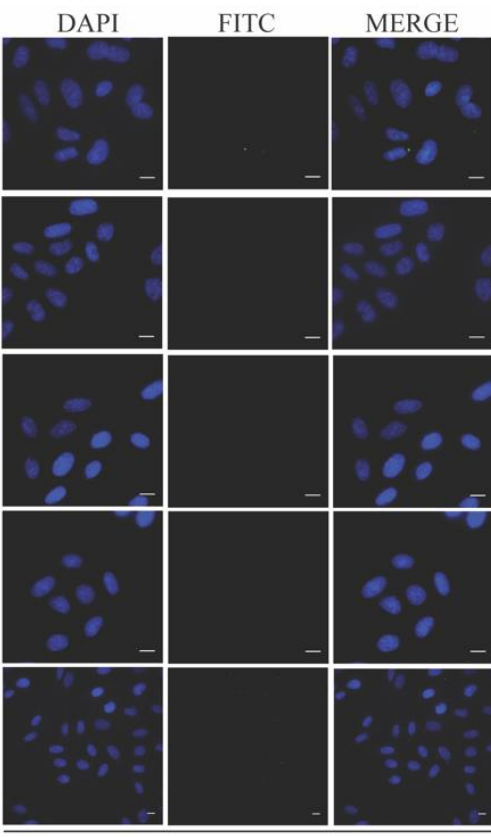

IFITM1/IFITM3 null

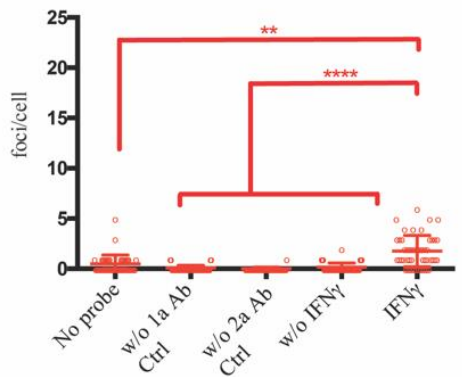

IFITM1/IFITM3 null

Figure 2. Evaluation of the IFITM1/IFITM3:HLA-B protein-RNA interaction in situ after stimulation with

IFN $\gamma$ by rISH-PLA. RNA in situ hybridization-PLA assays were used to study the endogenous interaction between HLA-B mRNA and IFITM1/3 proteins in wt-SiHa cells (A-E) and IFITM1/IFITM3 null cells (F-J). A biotinylated probe was designed to bind specifically the HLA-B mRNA. FITC images identify the protein-RNA association foci (green) and DAPI was used for nuclear staining (blue). (A-C and F-H) Cells were incubated as negative controls; without the RNA probe (A and F), using primary antibodies only (B and G), or secondary antibodies only ( $\mathrm{C}$ and $\mathrm{H}$ ). Cells were incubated with both IFITM1/IFITM3 and biotin antibodies to define protein-RNA foci in non-stimulated cells (D and I) or IFN $\gamma$-stimulated cells (E and J). Representative quantification of the protein-RNA interaction foci per cell in presence or absence of IFN stimulation in wt-SiHa cells (K) and IFITM1/IFITM3 null cells (L). At least 50 cells were counted in each condition. Statistical study was performed with one-way ANOVA and Bonferroni correction $\left({ }^{* * *} \mathrm{p}<0.0001,\left({ }^{* *} \mathrm{p}<0.01\right) . \mathrm{n}=3\right.$. Scale bar: $10 \mu \mathrm{m}$. 

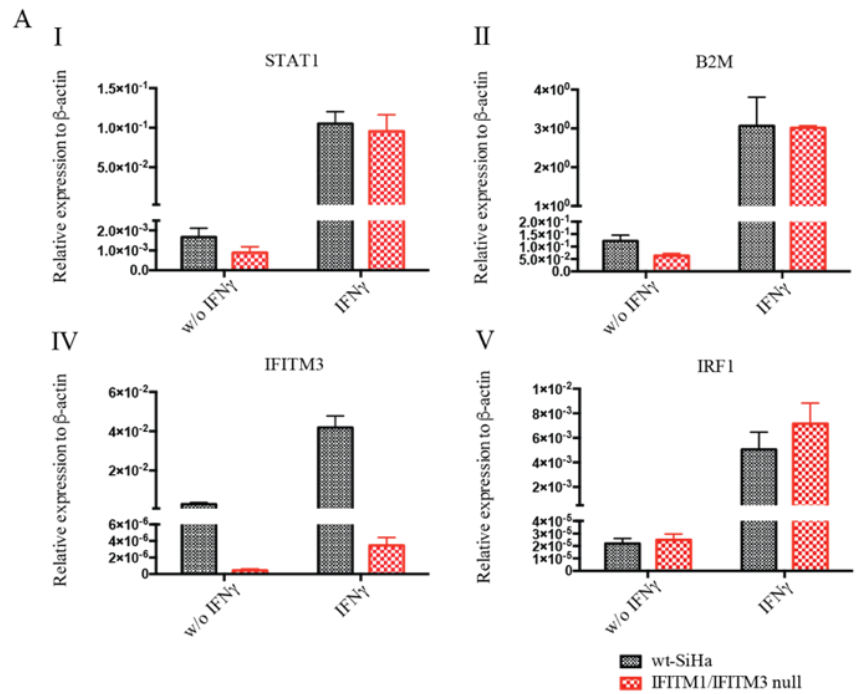

III

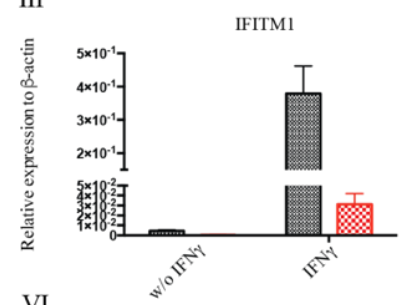

VI

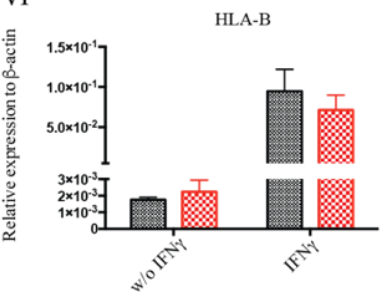

B
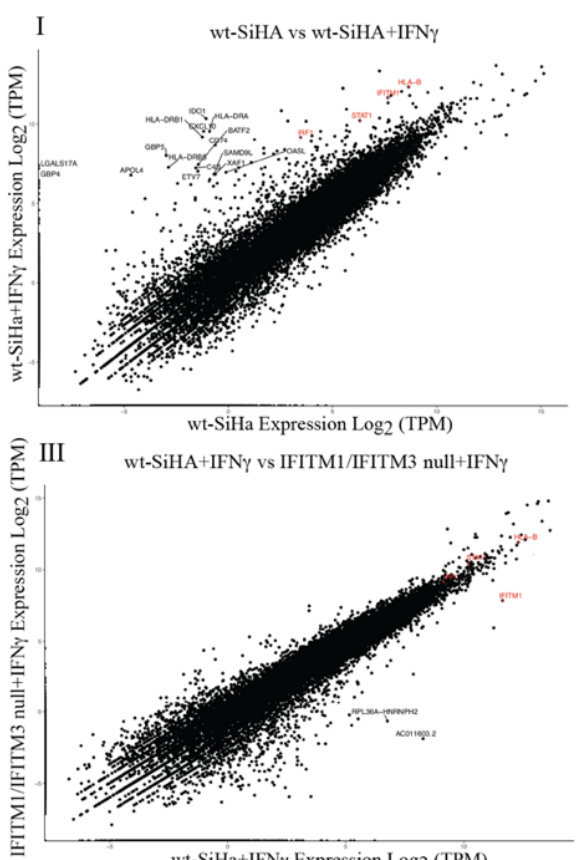
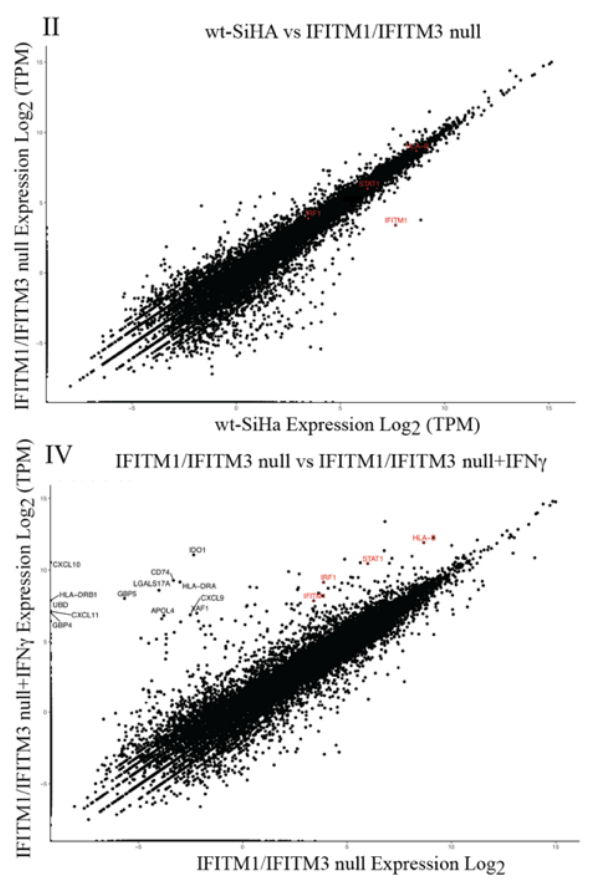

Figure 3. Validation of the transcript levels of IFN $\gamma$-stimulated genes in wt-SiHa cells and IFITM1/IFITM3 null cells unstimulated or IFN $\gamma$-stimulated for $24 \mathrm{~h}$. STAT1 (I), B2M(II), IFITM1 (III), IFITM3 (IV), IRF1 (V), HLA-B (VI) mRNA quantification by RT-qPCR in wt-SiHa (in black) and IFITM1/IFITM3 null cells (in red). Measurements were performed in untreated cells and after stimulation with $100 \mathrm{ng} / \mathrm{ml} \operatorname{IFN} \gamma$ for $24 \mathrm{~h}$. Error bars are a representation of the variability between three biological replicates. Each biological sample was run in three technical replicates. $\beta$-ACTIN was used to normalize the mRNA expression between samples. Statistical study was performed with two-way ANOVA and Bonferroni correction $\left({ }^{* * *} \mathrm{p}<0.0001{ }^{* * *} \mathrm{p}<0.001\right.$; $^{* *} \mathrm{p}<0.01$; ns, not significant). B. Comparison of total transcript count in wt-SiHa cells and IFITM1/IFITM3 null cells. Fastq files were imported into CLCBio Genomics workbench 12.0. The sequencing reads were used as the input file and RNA-seq analysis tool was used as the input for Create Fold Change Track drop down tab. All transcript reads detected were taken to generate the final transcript count for each gene (SI Appendix, Table S2). Comparisons of all transcripts identified are plotted for the following conditions: (I) non-treated wt-SiHa cells vs IFN $\gamma$ stimulated wt-SiHa cells, (II) non-treated wt-SiHa cells vs non-treated IFITM1/IFITM3 null cells, (III) IFN $\gamma$ - 
bioRxiv preprint doi: https://doi.org/10.1101/2022.02.02.478792; this version posted February 3, 2022. The copyright holder for this preprint (which was not certified by peer review) is the author/funder, who has granted bioRxiv a license to display the preprint in perpetuity. It is made available under aCC-BY 4.0 International license.

stimulated wt-SiHa cells vs IFN $\gamma$-stimulated IFITM1/IFITM3 null cells, (IV) non-treated IFITM1/IFITM3 null cells vs IFN $\gamma$-stimulated IFITM1/IFITM3 null cells. Each plot has highlighted in red STAT1, IFITM1, IRF1, ISG15 and HLA-B transcripts. Other significantly induced transcripts are additionally highlighted in black. Transcript expression is measured in Log2 of transcripts per million (TPM).

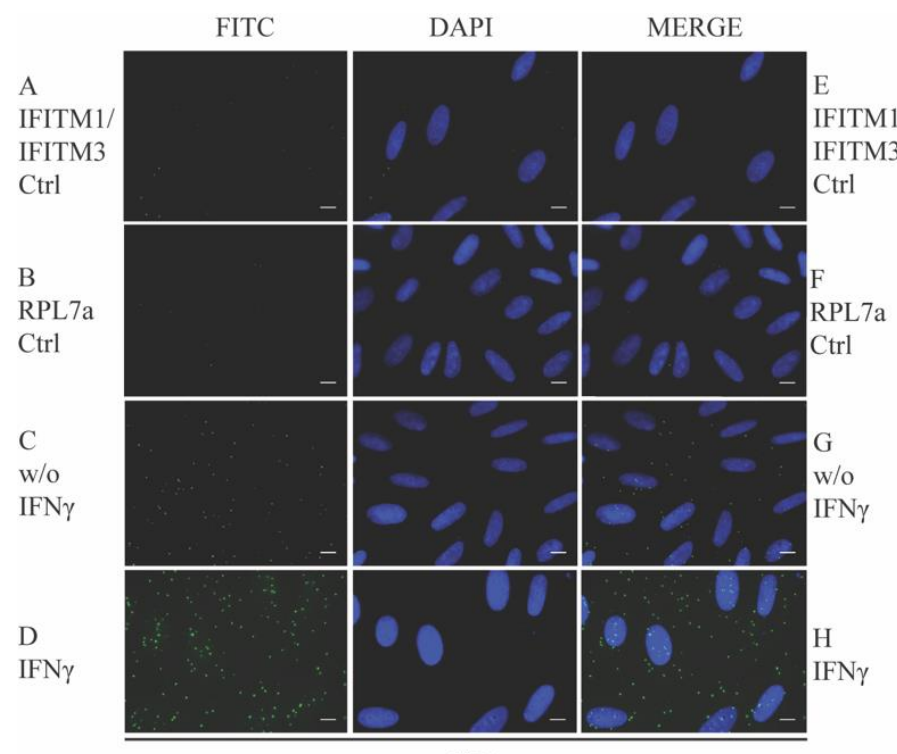

wt-SiHa

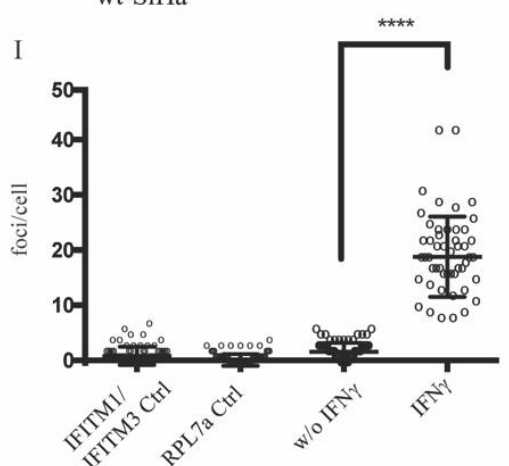

wt-SiHa

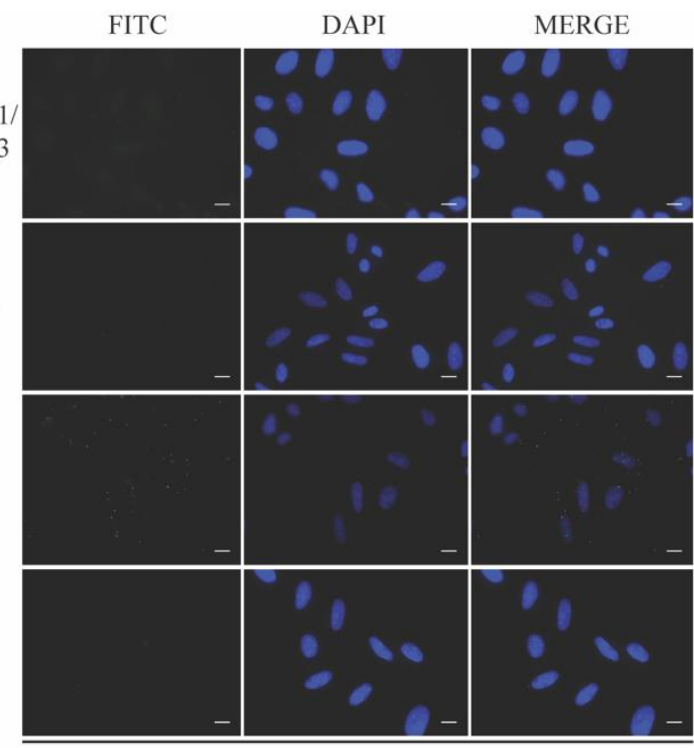

IFITM1/IFITM3 null

$\mathrm{J}$

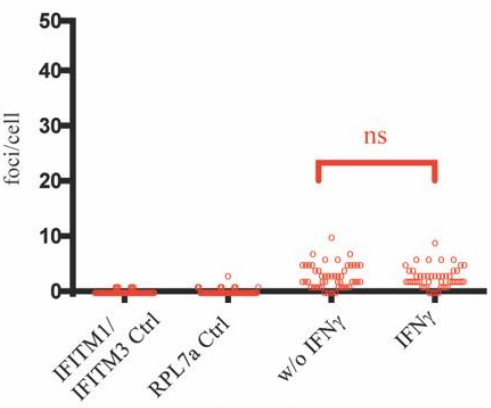

IFITM1/IFITM3 null

Figure 4. Evaluation of the IFITM1/IFITM3:RPL7a protein-protein expression and interaction in situ after RPL7a and IFITM1/IFITM3 proteins in wt-SiHa (A-D) and IFITM1/IFITM3 null cells (E-H) FITC images identify the protein-protein association foci (green) and DAPI was used for nuclear staining (blue). (A-B and E-F) Cells were incubated as negative controls using IFITM1/IFITM3 or RPL7a antibodies only. (C and G) Cells were incubated with both IFITM1/IFITM3 and RPL7a antibodies to define protein-protein foci in non-stimulated cells. (D and H) Cells were incubated with both IFITM1 and RPL7a antibodies to define protein protein foci in IFNstimulated cells. Representative quantification of the protein-protein interaction foci per cell in presence or absence of IFN stimulation in wt-SiHa (I) and IFITM1/IFITM3 null (J). At least 50 cells were counted for each condition. Statistical study was performed with one-way ANOVA and Bonferroni correction $\left({ }^{* * *} \mathrm{p}<0.0001\right.$; ns, not significant). $\mathrm{n}=3$. Scale bar: $10 \mu \mathrm{m}$. 


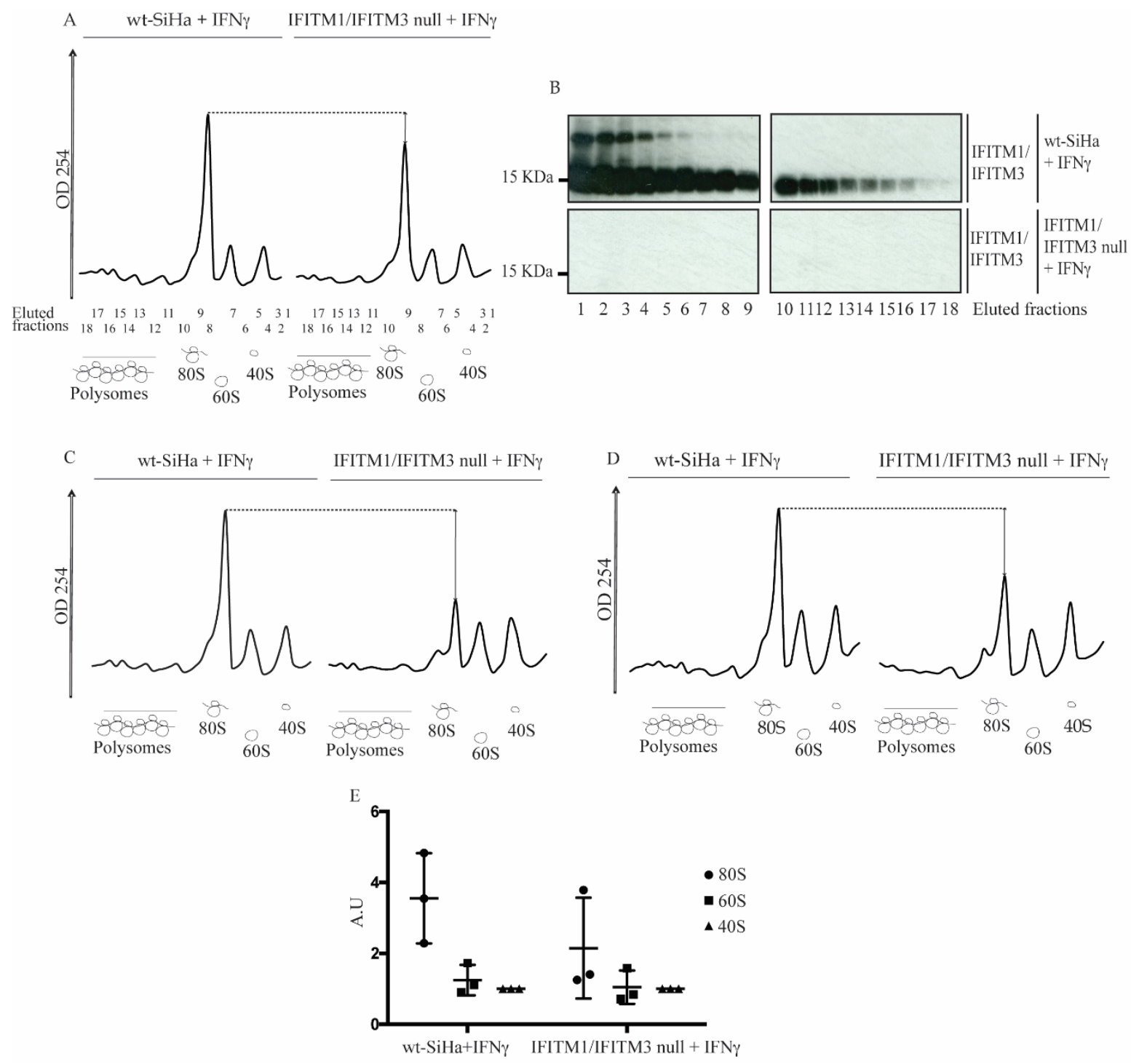

Figure 5. Ribosomal integrity analysis in IFN $\gamma$-stimulated wt-SiHa cells and IFITM1/IFITM3 null cells. (A, C, and D). The wt-SiHa cells and IFITM1/IFITM3 null cells were stimulated in three biological replicates with $100 \mathrm{ng} / \mathrm{ml}$ IFN $\gamma$ for $24 \mathrm{~h}$. The cells were lysed with ribosome stabilization buffer and applied to a $10-45 \%$ sucrose gradient to separate individual components of the large and small ribosomal subunits, and polysomal structures. Eluted fractions (numbered) were scanned at A254 nm and the diagram highlights the position of the 40S, 60S, 80 , and poly-ribosomal subunits. The dotted line highlights the reproducible reduction in the A254 signal in eluates from the IFITM1/IFITM3 null cells. (B) Following fractionation of material from (A), samples from fractions 1-18 were precipitated by trichloroacetic acid and they were analyzed for IFITM1/3 protein expression (enriched in all wt-SiHa fractions). (E) Quantitation of the ratio of 40S, 60S, and $80 \mathrm{~S} \mathrm{A254} \mathrm{nm} \mathrm{peaks} \mathrm{in} \mathrm{wt-SiHa}$ cells and IFN $\gamma$-stimulated IFITM1/IFITM3 null cells. 


\section{Supplementary Information for} IFITM1/3 mediating protein expression

Maria Gómez-Herranz ${ }^{a, c^{*}}$, Jakub Faktor ${ }^{b, c}$, Marcos Yébenes Mayordomo ${ }^{a, c}$, Magdalena Pilch ${ }^{a, c}$, Lenka

aUniversity of Edinburgh, Institute of Genetics and Cancer, Edinburgh, United Kingdom;

* Correspondence should be addressed to: 
bioRxiv preprint doi: https://doi.org/10.1101/2022.02.02.478792; this version posted February 3, 2022. The copyright holder for this preprint (which was not certified by peer review) is the author/funder, who has granted bioRxiv a license to display the preprijh in perpetuity. It is made available under aCC-BY 4.0 International license.

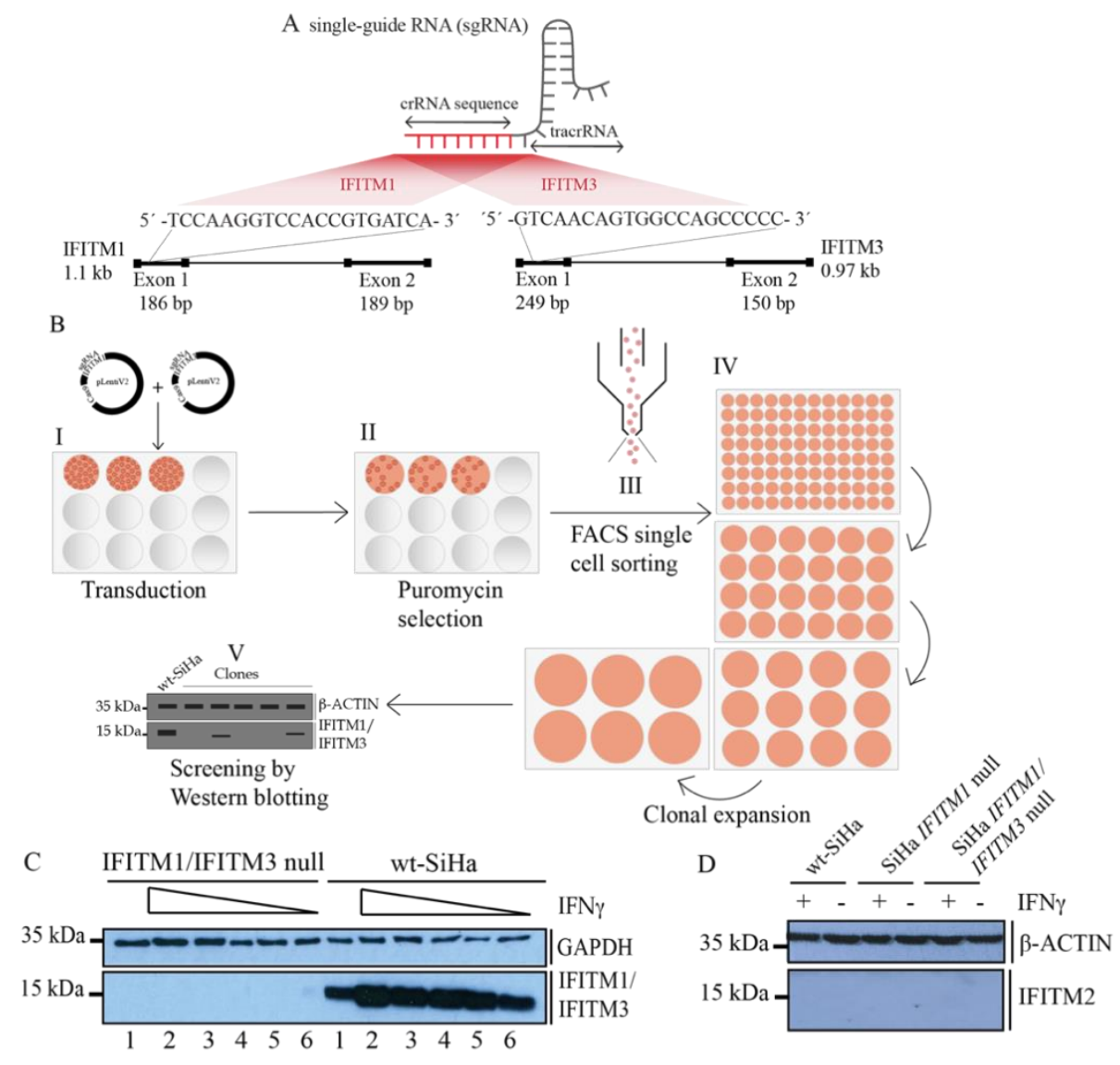

$\mathrm{E}$
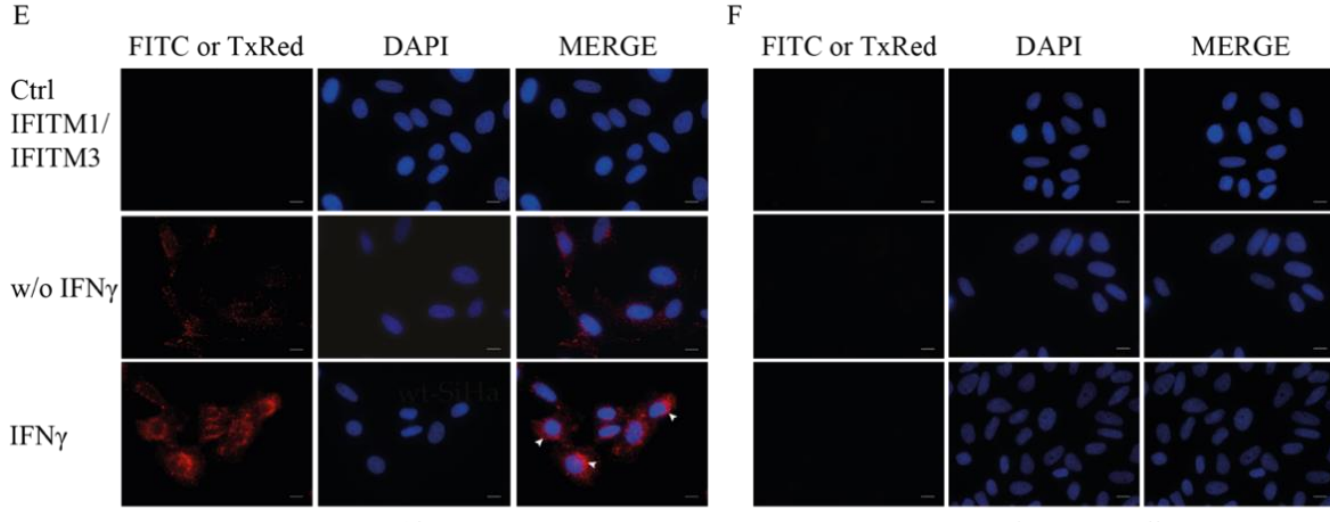

wt-SiHa

IFITM1/IFITM3 null

Figure S1. Workflow for generating IFITM1/3-knockout SiHa cells using CRISPR/Cas9 gene editing technology. (A)

Schematic of the CRISPR/Cas9 system. The sgRNA sequence was designed to target the genes of interest within the exon 1;

IFITM1 (5' -TCCAAGGTCCACCGTGATCA- 3') and IFITM3 (5' -GTCAACAGTGGCCAGCCCCC- 3'). (B) The wt-SiHa cells were transduced with pLentiV2 plasmid containing the Cas9 cassette, IFITM1 sgRNA or IFITM3 sgRNA to generate IFITM1/IFITM3-knockout cells (I). The IFITM1/IFITM3 null cells were generated by transducing pLentiV2 plasmid containing Cas9 cassette and IFITM3 sgRNA into IFITM1 null cells. The next day, medium with lentivirus was removed and the cells were resuspended in fresh media containing $10 \mu \mathrm{g} / \mathrm{ml}$ puromycin (II). Puromycin selection was continued for about two weeks, after which single cells were sorted by FACS into 96-well plates (III). These cells were propagated to form colonies originating from a single cell (IV) and cell clones were tested by Western blotting (V). (C) Dose dependent titration in wt-SiHa and IFITM1/IFITM3 null cells with IFN $\gamma$-stimulation for 24 h: non-treated (lane 1), 2000 (lane 2), 1000 (lane 3), 100 (lane 4), 50 (lane 5), and 10 (lane 6) $\mathrm{ng} / \mathrm{ml}$. Cells were tested by Western blotting using the IFITM1/IFITM3 antibody for detection (approximately $15 \mathrm{kDa}$ ). GAPDH 
expression to cells stimulated with $100 \mathrm{ng} / \mathrm{ml}$ IFN $\gamma$ for $24 \mathrm{~h}$. IFITM2 protein expression was not detected despite IFN $\gamma$-stimulation. Cells were tested by Western blotting using the IFITM2 antibody for detection (approximately $15 \mathrm{kDa}$ ). $\beta$-ACTIN (approximately $35 \mathrm{kDa}$ ) was used as a loading control. Wt-SiHa cells (E) and IFITM1/IFITM3 null (F) were grown to 80\% confluency and fixed with $4 \%(\mathrm{w} / \mathrm{v})$ paraformaldehyde, permeabilised using $0.25 \%$ Triton X-100 and blocked with 3\% (w/v) BSA. Immunofluorescence was performed detecting IFITM1/IFITM3 protein in non-stimulated cells (w/o IFN $\gamma$ ) or cells stimulated with $100 \mathrm{ng} / \mathrm{ml}$ IFN $\gamma($ IFN $\gamma$ ) for $24 \mathrm{~h}$. The negative control (Ctrl IFITM1/3) was performed by solely staining with anti-mouse Alexa Fluor 594

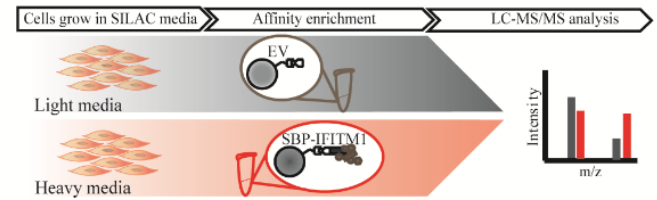

B

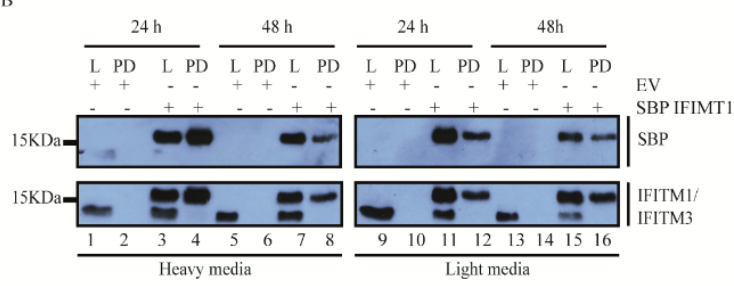

SRSF1

Isoform ASF-1 (accession number: Q07955) $24 \mathrm{KD}$

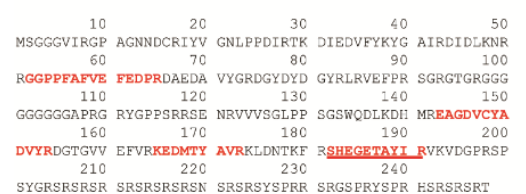

SRSF3

Isoform 1 (accession number: P84103) 19.3 KD

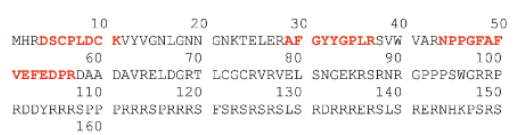

FSRSRSRSRS NERK

Figure S2. Identification of IFITM1 interacting proteins. (A) SILAC workflow describing the stages followed for identifying the IFITM1 binding proteins using SBP-tagged IFITM1 and SBP empty-vector control; stage include cell labelling, transfection, affinity purification using streptavidin beads, elution of the IFITM1 complexes, FASP and LC-MS/MS analysis. (B) An immunoblot of lysates from cells transfected with SBP-tagged IFITM1 or SBP empty vector. Cells were harvested after 24 and 48 $\mathrm{h}$ following SBP-IFITM1 or SBP-vector transfection. Transfections were performed in cells grown with heavy and light SILAC media. Lanes were loaded with Lysate [L] and Pull-down [PD]. SBP-tagged IFITM1 was detected in lysates of transfected cells grown in heavy (R6K6) media (lanes 1-8) or light (R0K0) media (lanes 9-16). The transfected SBP-IFITM1 protein was detected in the lysate using either anti-SBP antibody (top panel) or IFITM1/IFITM3-specific monoclonal antibody (lower panel; lanes 3, 7, 11 and 15). SBP-IFITM1 protein was detected by a migration at $19 \mathrm{kDa}$ and the endogenous IFITM1/IFITM3 proteins migrated at a position of $13.9 \mathrm{kDa}$ and $14.6 \mathrm{kDa}$, respectively. The transfected SBP-IFITM1 protein was detected in the lysate at either 24 or $48 \mathrm{~h}$ post-transfection into cells with heavy media (lanes 3 and 7) or light media (lanes 11 and 15). (C) Overlapping of proteins 
bioRxiv preprint doi: https://doi.org/10.1101/2022.02.02 478792; this version posted February 3, 2022. The copyright holder for this preprint (which was not certified by peer review) is the author/funder, who has granted bioRxiv a license to display the preprint in perpetuity. It is made available under aCC-BY 4.0 International license.

detected by MS from 24 or $48 \mathrm{~h}$ post transfection and affinity purification of SBP-IFITM1 including the top proteins enriched in the IFITM1 enrichment (from SI Appendix, Table S1). (D) Identified SRSF peptides in SBP-IFITM1 protein enrichment after affinity purification in isotopically labelled wt-SiHa cells. Heavy isotopically labelled tryptic peptides identified from the SBPIFITM1 affinity enrichment are highlighted in red for the SRSF family of proteins (SRSF1, SRSF2, SRSF3, SRSF6 and U2AF1).

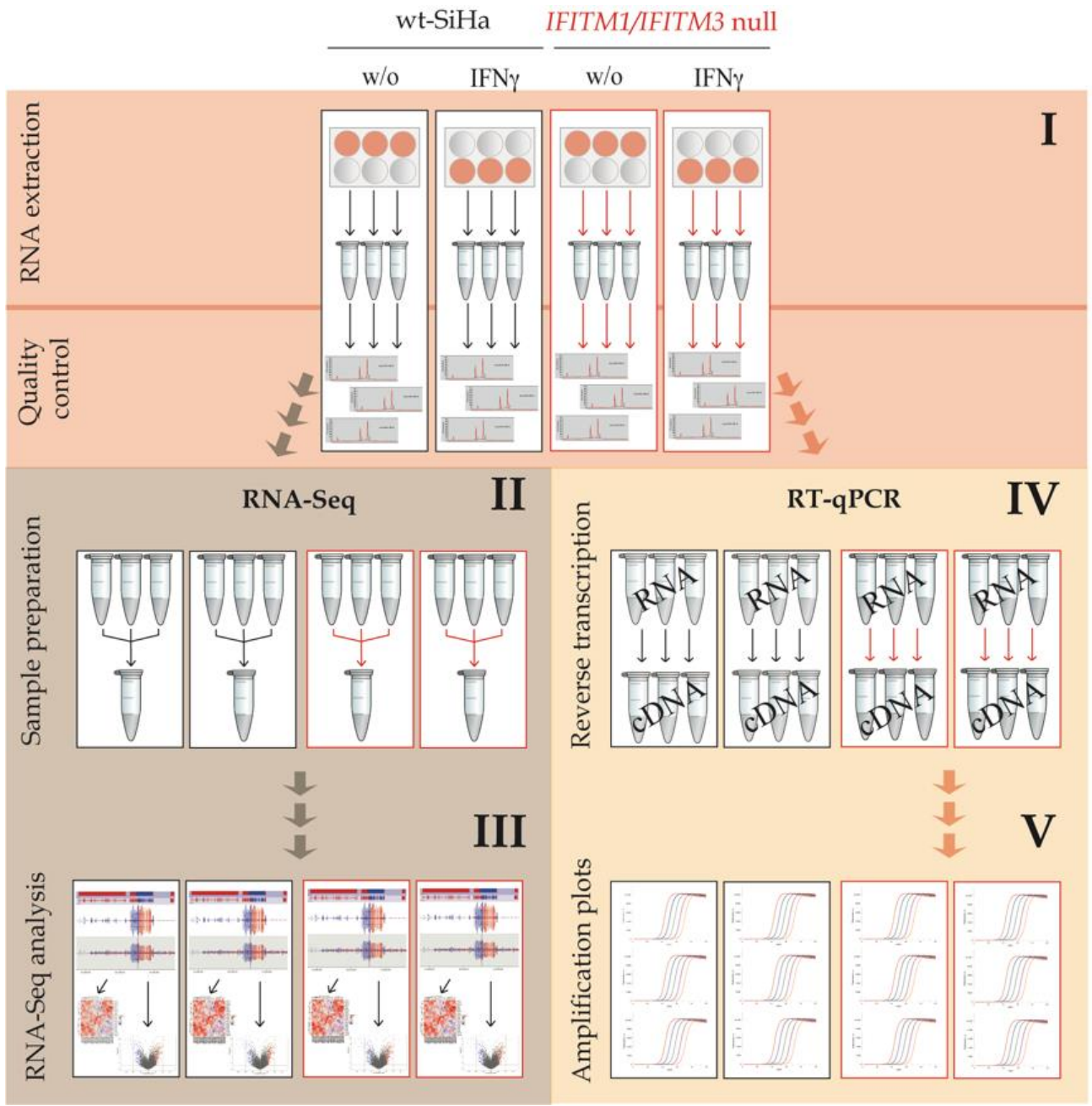

Figure S3. Workflow followed to analyze the transcriptome in wt-SiHa cells and IFITM1/IFITM3 null cells. (I) RNA was extracted from non-stimulated or IFN $\gamma$-stimulated cells using three biological replicates. Aliquots of total RNA from the three biological replicates were used for (II) next-generation RNA Seq analysis using the Illumina PE100-125 and HiSeq2500 sequencing platform. PolyA+ RNA pools were purified and used to generate cDNA for fragmentation, PCR amplification, and DNA sequencing according to Illumina methodologies. (III) The fastq files representing $20 \mathrm{M}$ reads were imported and analyzed using CLC Genomics Workbench with GRCh38 as a reference genome. The global analysis of IFN $\gamma$ responsive gene sets is plotted in Fig 3B I-IV and as a subset of the IFN $\gamma$ responsive proteins, IRDS, as a heat map (SI Appendix, Fig. S4). (IV) Remained material from the RNA extraction was further used to analyze transcripts of interest by RT-qPCR using the three biological replicates (Fig 


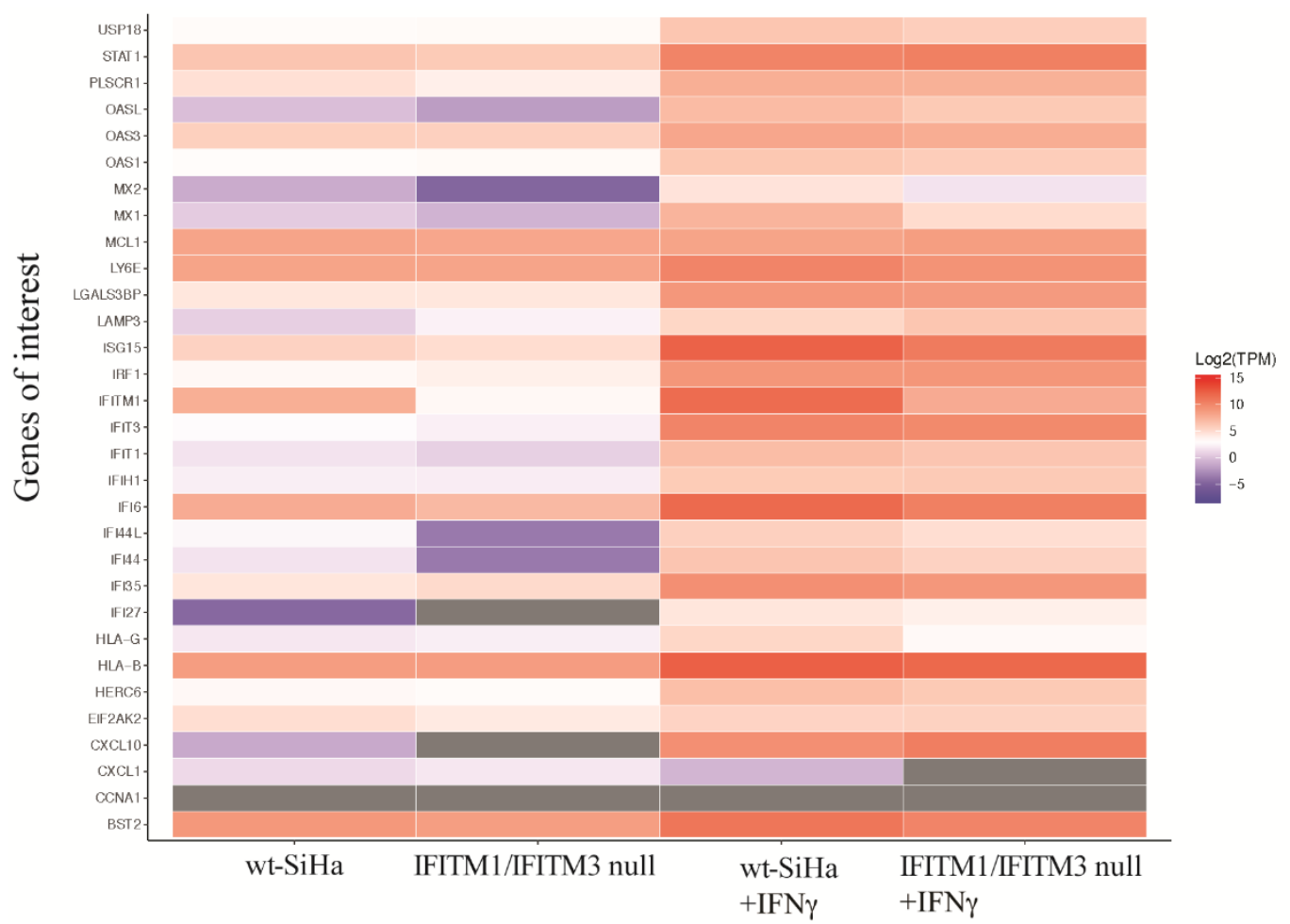

1011 Figure S4. Heat map representation of the mRNA induction of the 31 IRDS genes. The $\mathrm{x}$-axis contains the wt-SiHa and IFITM1/IFITM3 null cells non-stimulated or IFN $\gamma$-stimulated with $100 \mathrm{ng} / \mathrm{ml}$ for $24 \mathrm{~h}$. The y-axis contains transcript expression corresponding to the 31 IRDS genes. Color scale units are $\log 2$ (TMP), becoming red when it is highly expressed and purple to blue for non-expressed and under-expressed values. Values in grey color correspond to genes which TPM was equal to 0. TPM=transcript per million. The heatmap was developed by taking the $\log 2$ (TPM) count of the 31 IRDS genes; representation of the genes of interest (IRDS) is extracted from SI Appendix, Table S2. R version 3.5.3 and ggplot2 3.2.1 was to create the heatmaps. 
bioRxiv preprint doi: https://doi.org/10.1101/2022.02.02.478792; this version posted February 3, 2022. The copyright holder for this preprint (which was not certified by peer review) is the author/funder, who has granted bioRxiv a license to display the preprint in perpetuity. It is made available under aCC-BY 4.0 International license.

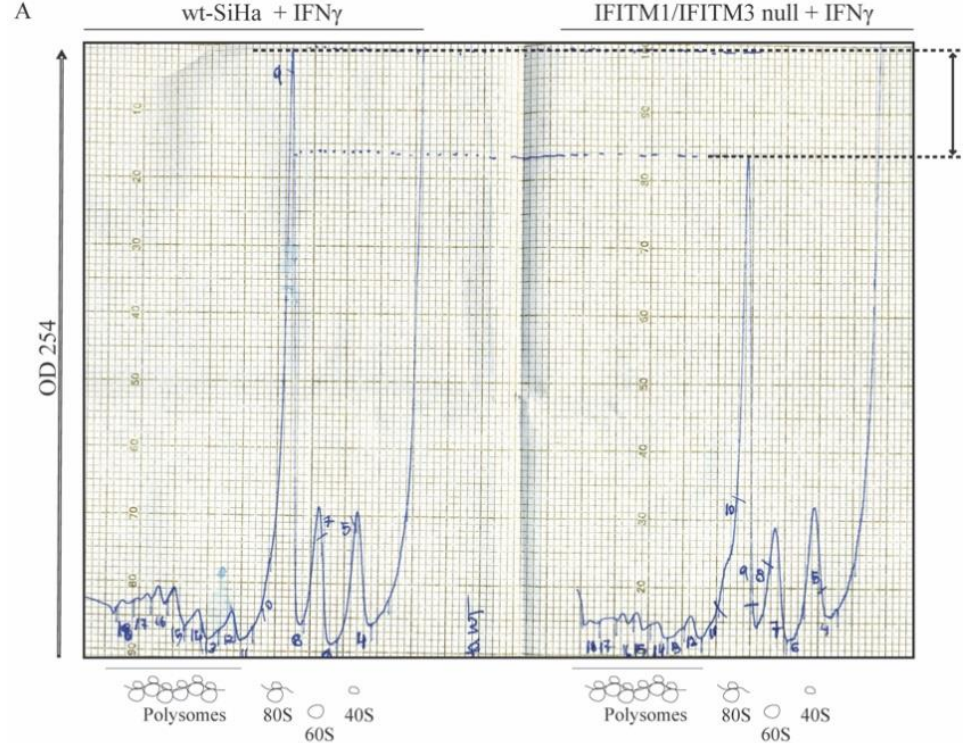

B

IFITM1/IFITM3 null + IFN $\gamma$

wt-SiHa + IFN $\gamma$

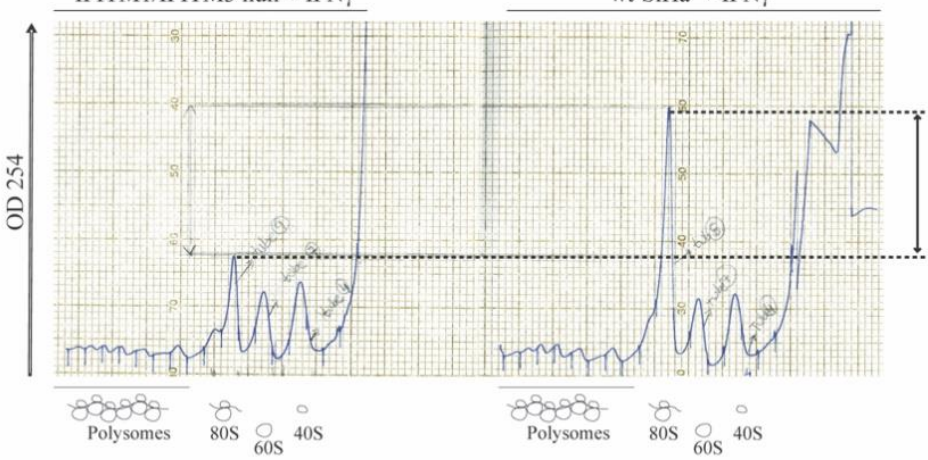

C

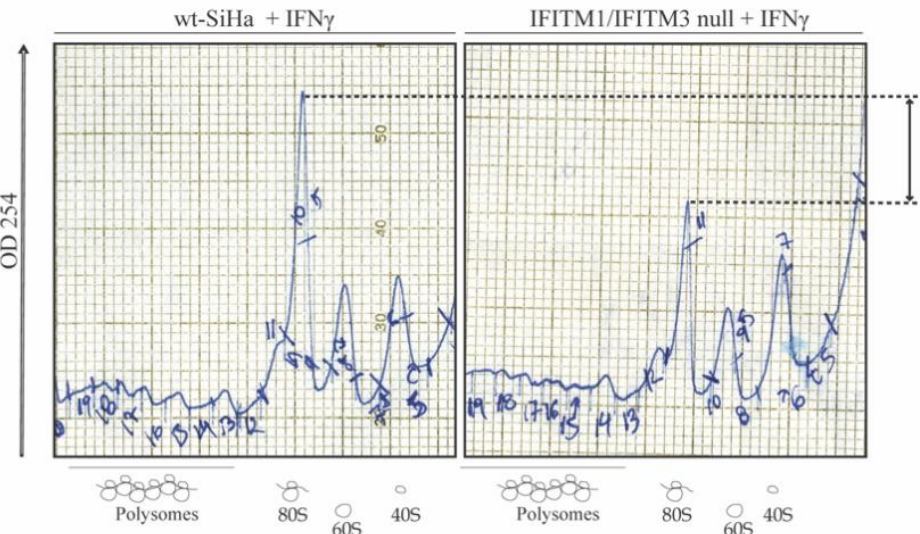


bioRxiv preprint doi: https://doi org/10 1101/2022 02.02 .478792 ; this version posted February 3, 2022. The copyright holder for this preprint (which was not certified by peer review) is the author/funder, who has granted bioRxiv a license to display the preprint in perpetuity. It is made available under aCC-BY 4.0 International license.
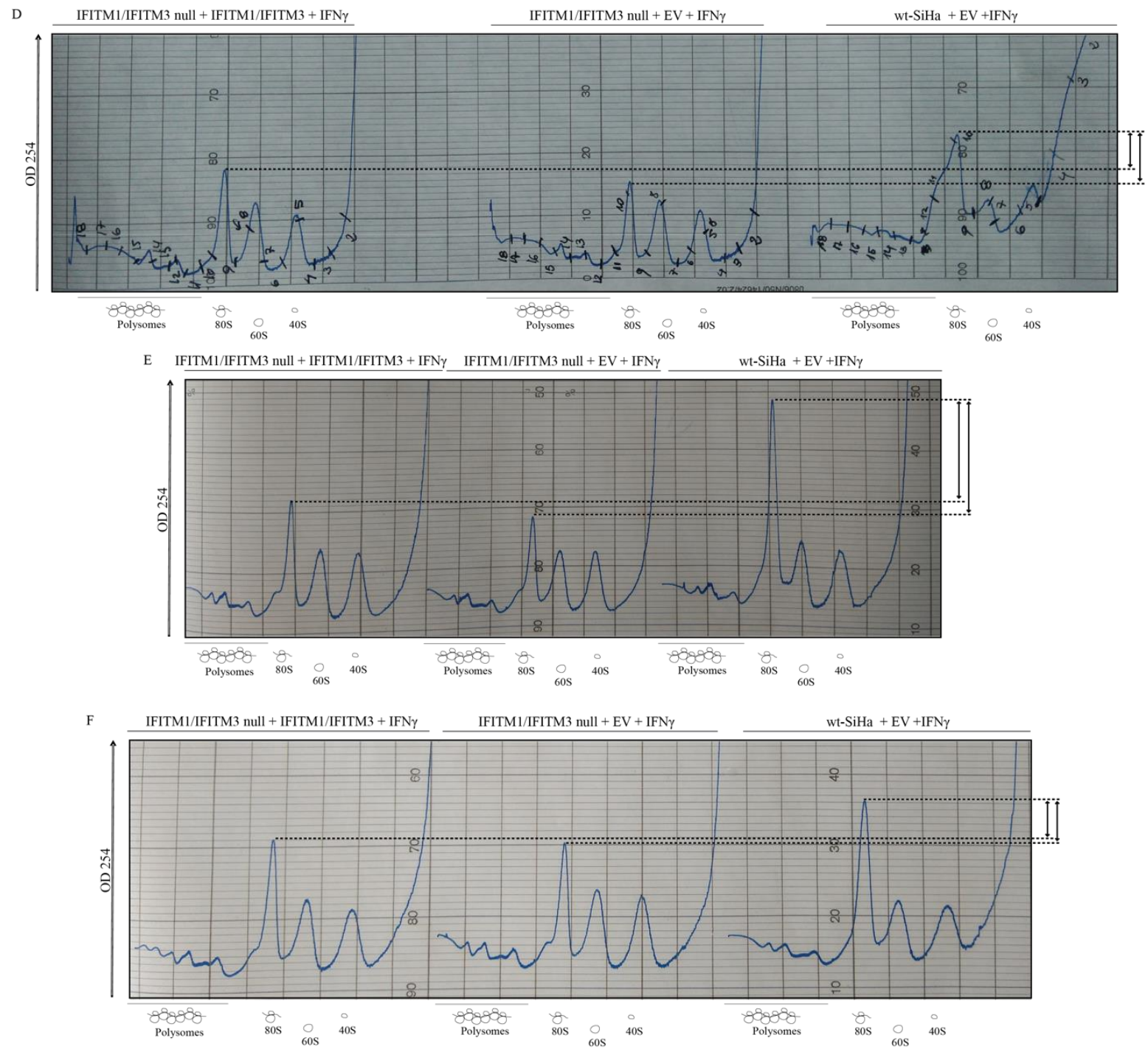

Figure S5. Original scans for the mRNA trace after sucrose density gradient fractionation in six independent replicates. IFITM1/IFITM3 null cells in all three replicates (indicated with the dashed lines). (D-F) Sucrose density gradient was performed in wt-SiHa cells and IFITM1/IFITM3 null cells treated with $100 \mathrm{ng} / \mathrm{ml} \mathrm{IFN} \gamma$ for $24 \mathrm{~h}$. Cells were also transfected with IFITM1 and IFITM3, or the respective empty vector (EV) for $48 \mathrm{~h}$ to recover the lower $80 \mathrm{~S}$ peak observed in the IFITM1/IFITM3 null cells 
Table S1. List of proteins enriched in SBP-IFITM1 pull down. The precipitates at both 24 and $48 \mathrm{~h}$ transfection times were processed as in the experimental methods. The data in the multiconsensus report are represented, as in column: A. Accession number, B. Description (gene name). Summary from all analyzed samples. C. $\Sigma$ Coverage (the number of amino acids in a protein sequence that were found in identified peptides), D. $\Sigma \#$ Proteins (number of proteins identified in the protein group; introduced is the master protein), E. $\Sigma \#$ Unique Peptides (number of peptides that are unique to a protein group), F. $\Sigma \#$ Peptides (the total number of distinct peptides in protein group), G. $\Sigma \# P S M S$ (the number of peptide spectrum matches, the total number of spectra used for the identification of the peptides belongs to the protein). $24 \mathrm{~h}$ time point; H. XCorr (the goodness of fit of experimental peptide fragments to theoretical spectra created from the sequence $b$ and $y$ ions)); I Coverage, J. \# Peptides, K. \#PSM, and L. Area (under the peak, value used for quantification). $48 \mathrm{~h}$ time point; M, XCorr; N Coverage, O \# Peptides, P. \#PSM, and Q. Area. The ratio of the relative peak intensities of the heavy to light peptides are highlighted at $24 \mathrm{~h}(\mathrm{R})$ and $48 \mathrm{~h}(\mathrm{U})$.

Table S2. Generation of RNA seq datasets from the indicated cell lines using CLCBio Genomics workbench 12.0. The fastq sequencing reads were used as the input file and RNA-seq analysis tool was used in the CLCbio Genomics workbench 12.0. All transcript reads detected were taken to generate the final transcript count for each gene. Comparisons of all transcripts were performed for the following cells: non-treated wt-SiHa cells (index 13 fastq files), IFN $\gamma$-stimulated wt-SiHa cells (index 14 fastq files), non-treated IFITM1/IFITM3 null cells (index 23 fastq files), and vs IFN $\gamma$-stimulated IFITM1/IFITM3 null cells (index 25 fastq files). The output excel file from the software in the columns represent: gene name; chromosome location; region; identifier; wild type SiHa total counts; wild type SiHa RPKM; wild type SiHa TPM; wild type SiHa CPM; wild type SiHa IFN $\gamma$ total counts; wild type $\mathrm{SiHa}$ IFN $\gamma$ RPKM; wild type $\mathrm{SiHa}$ IFN $\gamma \quad \mathrm{TPM}$; wild type SiHa IFN $\gamma$ CPM; IFITM1/IFITM3 null total counts; IFITM1/IFITM3 null RPKM; IFITM1/IFITM3 null TPM; IFITM1/IFITM3 null CPM; IFITM1/IFITM3 null IFN $\gamma$ total counts; IFITM1/IFITM3 null IFN $\gamma$ RPKM; IFITM1/IFITM3 null IFN $\gamma \quad$ TPM; IFITM1/IFITM3 null IFN $\gamma \quad$ CPM. 